\title{
Autophagy induced by a sulphamoylated estrone analogue contributes to its cytotoxic effect on breast cancer cells
}

\author{
Marcel Verwey*, Elsie M. Nolte, Anna M. Joubert and Anne E. Theron
}

\begin{abstract}
Background: Autophagy can either be protective and confer survival to stressed cells, or it can contribute to cell death. The antimitotic drug 2-ethyl-3-O-sulpamoyl-estra-1,3,5(10),15-tetraen-17-ol (ESE-15-ol) is an in silico-designed $17-\beta$-estradiol analogue that induces both autophagy and apoptosis in cancer cells. The aim of the study was to determine the role of autophagy in ESE-15-ol-exposed human adenocarcinoma breast cancer cells; knowledge that will contribute to future clinical applications of this novel antimitotic compound. By inhibiting autophagy and determining the cytotoxic effects of ESE-15-ol-exposure, deductions could be made as to whether the process may confer resistance to the drug, or alternatively, contribute to the cell death process.
\end{abstract}

Methods and results: Spectophometrical analysis via crystal violet staining was used to perform cytotoxicity studies. Morphology studies were done using microscopic techniques namely polarization-optical transmitted light differential interference light microscopy, fluorescent microscopy using monodansylcadaverine staining and transmission electron microscopy. Flow cytometry was used to quantify the autophagy inhibition and assess cell viability. Results obtained indicated that 3-methyladenine inhibited autophagy and increased cell survival in both MCF-7 and MDAMB-231 cell lines.

Conclusion: This in vitro study inferred that autophagy inhibition with 3-methyladenine does not confer increased effectiveness of ESE-15-ol in inducing cell death. Thus it may be concluded that the autophagic process induced by ESE-15-ol exposure in MCF-7 and MDA-MB-231 cells plays a more significant role in cell death than conferring survival.

Keywords: Breast cancer, Autophagy, Apoptosis, Cell survival, ESE-15-ol, 3-Methyladenine

\section{Background}

2-Methoxyestradiol (2ME), a microtubule depolymerising agent, is both an anti-cancer and anti-angiogenic drug that has shown promise in cancer research (Fig. 1a) [1-3]. Although it is formed through the sequential endogenous metabolism of 17- $\beta$-estradiol, the compound exerts its cytotoxic effect independently of the cellular estrogen receptors and has no significant systemic hormonal effects [1-4]. $2 \mathrm{ME}$ is able to inhibit cancer cell proliferation, whereas estradiol promotes proliferation of cancer cells. 2ME inhibits hypoxiainducible factor- $1 \alpha$ (HIF- $1 \alpha$ ) which, in return causes inhibition of angiogenesis, as well as disruption of microtubules

*Correspondence: marcelverwey4@gmail.com

Department of Physiology, Faculty of Health Sciences, University of Pretoria, Private Bag X323, Arcadia, Pretoria 0007, Gauteng, South Africa
$[2,5]$. 2ME causes both the intrinsic- and extrinsic apoptotic pathways to be up-regulated by decreasing B-cell lymphoma 2 (Bcl-2) which has anti-apoptotic properties, or by increasing the death receptor 5 (DR5) $[2,5]$. Actively proliferating cells, such as cancer cells, are the main target for this druginduced apoptosis while preferential sparing of normal, quiescent endothelial cells is observed [3, 6]. 2ME not only causes a $\mathrm{G}_{1}$ cell cycle arrest, but also a $\mathrm{G}_{2} / \mathrm{M}$ arrest $[3,7]$. However, the molecular mechanism induced by $2 \mathrm{ME}$ differs between cell lines [5]. 2ME has undergone clinical trials for solid tumors, but shows limited bioavailability and rapid degradation in vivo $[1-3,8]$.

2-Ethyl-3-O-sulpamoyl-estra-1,3,5(10),15-tetraen17-ol (ESE-15-ol), a derivative of 2-ethyl-3-O-sulpamoyl-estra-1,3,5(10),15-tetraen-17-one (ESE-15-one) 


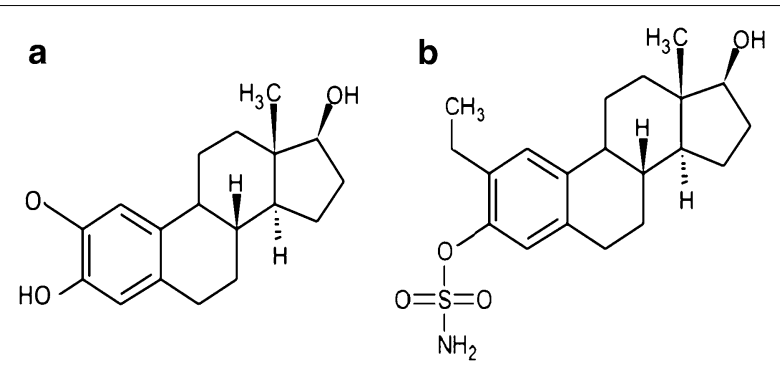

Fig. 1 Structure of 2-methoxyestradiol and ESE-15-ol. a 2-Methoxyestradiol is the parent compound of ESE-15-Ol; b ESE-15-ol is a novel sulphamoylated estradiol analogue

is a novel sulphamoylated estradiol analogue (Fig. 1b) [9]. ESE-15-ol is an anti-mitotic compound that binds to the colchicine binding site on microtubules, and is equally effective in both hormone-receptor positiveand negative cancer types [9-11]. ESE-15-ol induces both autophagy and apoptosis in breast cancer cells [9]. This potential anticancer drug was in silico-designed to increase the parent compound's bioavailability via carbonic anhydrase II (CAII) binding by the addition of a sulphamate group at the $C^{\prime} 3$ position [9]. The latter enzymatic binding occurs in erythrocytes and results in a slower release of drugs into the circulation, thereby bypassing the hepatic first-pass metabolism $[9,12,13]$. Tumors have acidic micro-environments in which CAIX convert carbon dioxide $\left(\mathrm{CO}_{2}\right)$ to carbonic acid [14]. This acidic environment enhances metastatic spread due to proteinase release $[9,15]$. Therefore the molecule was designed to also have an increased binding affinity to CAIX over CAII. By binding to CAIX, ESE-15-ol should selectively locate to solid tumours and potentionally improve chemotherapy by reducing the acidic surrounding, thereby decreasing metastasis [9].

Apoptosis is an energy-dependant mode of cell death and is also known as programmed cell death type I [16-18]. If apoptosis is down-regulated it permits tumor growth and multi-drug resistance [18]. Type IIprogrammed cell death is a degradative process known as autophagy which is associated with the formation of autophagic vesicles $[19,20]$. Literature points at a possible dual role associated with autophagy since it can contribute to either cell survival or cell death, depending on a myriad of different conditions $[19,20]$. It may promote survival by facilitating an adaptive response to cellular stress through providing an alternative source of energy during starvation. Additionally, autophagy can increase cell survival by protecting them from apoptosis through the down-regulation of pro-apoptotic proteins [19]. However, prolonged autophagy can lead to cell death due to the high protein turnover rate [21]. Autophagy and apoptosis are interconnected and share common stimuli for the execution of both pathways. Apoptosis and autophagy can thus either have synergistic or antagonistic effects [22].

3MA, a nucleotide derivative, is an inhibitor of autophagy [23]. 3MA blocks autophagy through inhibiting class I and class III phosphatidylinositide-3-kinases (PI3K) [23, 24]. Class III PI3K is a lipid protein that phosphorylates the 3rd position on the inositol ring in phosphatidylinositol to form phosphatidylinositol3-phosphate (PI3P), which is essential for the initial steps in autophagy [23]. This leads to the activation of protein kinase B (Akt) which then phosphorylates the mechanistic target of rapamycin (mTor) [20, 23]. 3MA can suppress cell invasion and migration of fibrosarcoma cells (HT1080) by inhibiting class III PI3K [25].

Studies by Xie et al. [27] and Li et al. [26] have shown that autophagy inhibition by 3-methyladenine (3MA) increased apoptotic cell death in human colon cancer cell lines and human hepatoma cells (HepG2). By inhibitiong the protective mechanism of autophagy, chemoresistance was overcome. However, Bonet-Ponce et al. [28] demonstrated that inhibition of autophagy by $3 \mathrm{MA}$ inhanced cell survival through reducing the oxidative stressinduced cell death. This indicates that the mechanisms of autophagy are cell and drug dependant.

In this study autophagy inhibition with 3MA during ESE-15-ol exposure was conducted to allow insight into whether autophagy will confer resistance to drugexposed cells, or whether it will contribute to programmed cell death.

\section{Methods}

\section{Reagents}

Dulbecco's minimum essential medium Eagle (DMEM), trypsin-EDTA, 3-methyladenine (3MA) and all other reagents not specifically mentioned were of analytical grade and purchased from Sigma-Aldrich (St. Louis, USA). Streptomycin, fungizone and penicillin were manufactured by Thermo Fisher Scientific (Massachusette (MA), USA). Crystal violet, gluteraldehyde and triton X-100 were purchased from Merck (Darmstadt, Germany). Anti-LC3B/MAP1LC3B-antibody was supplied by Novus Biological [Littleton, Colorado (CO), USA].

\section{Chemical compounds and appropriate controls}

The novel estradiol analogue, ESE-15-ol, was synthesized by Ithemba Pharmaceuticals (PTY) Ltd. (Modderfontein, Gauteng, South Africa) as it is not commercially available. A working $1 \mathrm{mM}$ stock solution of ESE-15-ol in dimethyl sulfoxide (DMSO) was prepared at the Department of Physiology, University of Pretoria and stored at $-20{ }^{\circ} \mathrm{C}$. DMSO was used as a vehicle control, never 
exceeding a $0.05 \%$ concentration in the final dilution. Actinomycin D (Sigma-Aldrich, St Louis, USA) was used as a positive control for apoptosis at a final concentration of $0.1 \mu \mathrm{g} / \mathrm{ml}$. A final concentration of $20 \mu \mathrm{M}$ tamoxifen (Sigma-Aldrich, St Louis, USA) was used as a positive control for autophagy. Tamoxifen $(20 \mu \mathrm{M})$ combined with $5 \mathrm{mM}$ 3MA was used as a positive control for autophagy inhibition. All chemicals were of analytical grade and purchased from Sigma-Aldrich (St Louis, USA), unless otherwise stated.

\section{Cell lines and general cell culture protocols}

For this in vitro study, the human adenocarcinoma breast cancer MCF-7 cell line and the metastatic human adenocarcinoma breast cancer MDA-MB-231 cell line were used (Cellonex, Johannesburg, South Africa). Penicillin $\mathrm{G}(100 \mathrm{U} / \mathrm{ml})$, fungizone $(250 \mu \mathrm{g} / \mathrm{l})$, streptomycin $(100 \mu \mathrm{g} / \mathrm{l})$ and $10 \%$ heat activated fetal calf serum (FCS) (Gibco ${ }^{\circledR}$ Invitrogen, California, USA) were added to DMEM. For the 96 well plates, 5000 cells were seeded in $200 \mu \mathrm{l}$ growth medium in each individual well. For the 6 well plates, 375,000 cells were seeded in $3 \mathrm{ml}$ growth medium in each individual well. For the $25 \mathrm{~cm}^{2}$ culture flasks, $1 \times 10^{6}$ cells $/ 5 \mathrm{ml}$ growth medium were seeded. Cells were incubated in a Forma Scientific water-jacketed incubator (Ohio, USA) in a humidified atmosphere at 5\% $\mathrm{CO}_{2}\left(37^{\circ} \mathrm{C}\right)$ for $24 \mathrm{~h}$ before exposure to ESE-15-ol, with or without 3MA. A final concentration of $5 \mathrm{mM} 3 \mathrm{MA}$ was used to inhibit autophagy during exposure with ESE15-ol or tamoxifen. Cells were pre-exposed to 3MA for an hour prior to addition of ESE-15-ol or tamoxifen.

\section{Spectrophotometry: crystal violet}

Crystal violet is a triarylmethane dye (purple) that stains the deoxyribonucleic acid (DNA) within cells in a monolayer culture. Cytotoxicity of a drug may be determined by measuring the absorbance of the crystal violet stained cells via spectrophotometry. The half maximal growth inhibitory concentration $\left(\mathrm{GI}_{50}\right)$ may thus be determined $[29,30]$. After a 24 h-exposure to an ESE-15-ol dose concentration series, $100 \mu \mathrm{l} 1 \%$ gluteraldehyde was added to the cells and samples were incubated for $15 \mathrm{~min}$ at room temperature. Gluteraldehyde was discarded and $100 \mu \mathrm{l}$ $0.1 \%$ crystal violet was added for $30 \mathrm{~min}$ for staining to take place. Crystal violet was discarded and the plate was washed under running tap water $( \pm 10 \mathrm{~min})$. Plates were left to dry for $24 \mathrm{~h}$. Triton X-100 $(0.2 \%)(200 \mu \mathrm{l})$ was added to the wells and samples were incubated for $40 \mathrm{~min}$ at room temperature for solubilisation. After incubation, $100 \mu \mathrm{l}$ of the solution was pipetted to a clean 96 well plate. Absorbance was read using the ELx800 Universal Microplate Reader (Bio-tek Instruments Inc. Vermont, USA) at $570 \mathrm{~nm}$.

\section{Polarization-optical transmitted light differential interference microscopy}

Viable cells were seeded at a density of 375,000 cells $/ 3 \mathrm{ml}$ growth medium in 6 well plates. After attachment, cells were exposed to ESE-15-ol in the presence or absence of $3 \mathrm{MA}$ for $24 \mathrm{~h}\left(37^{\circ} \mathrm{C}\right)$ along with appropriate controls. PlasDIC images were viewed at a $40 \times$ magnification with a Zeiss Axiovert-40 microscope (Göttingen, Germany) and captured with the Zeiss Axiovert MRm monochrome camera (Göttingen, Germany).

\section{Fluoresence microscopy}

Cells were exposed to ESE-15-ol in the presence or absence of $3 \mathrm{MA}$ for $24 \mathrm{~h}\left(37^{\circ}\right)$ along with the appropriate controls. Cells were stained with $0.05 \mathrm{mM}$ monodansylcadaverine (MDC) in PBS for $10 \mathrm{~min}\left(37^{\circ} \mathrm{C}\right)$ and protected against light after which cells were washed four times with PBS. Using the Zeiss inverted Axiovert CFL 40 microscope and the Zeiss Axiovert MRm monochrome camera (Göttingen, Germany) fluorescent images were visualized with a UV filter with excitation of $380 \mathrm{~nm}$ and emission of $480 \mathrm{~nm}$ at a $40 \times$ magnification.

\section{Transmission electron microscopy}

After $24 \mathrm{~h}$ of exposure to ESE-15-ol with or without 3MA alongside all the appropriate controls, cells were trypsinized and fixed in $2.5 \%$ gluteraldehyde in $0.075 \mathrm{M}$ phosphate buffer for $1 \mathrm{~h}$ (room temperature). Cells were washed three times for $10 \mathrm{~min}$ with $0.075 \mathrm{M}$ phosphate buffer followed by fixation in $0.5 \%$ aqueous osmium tetroxide for $1 \mathrm{~h}$ (room temperature). Cells were washed 3 times in distilled water. Increasing ethanol concentrations (10, 30, 50, 70 and 100\%) were used to dehydrate the fixed cells for $10 \mathrm{~min}$ in each concentration. Quetol $(30 \%)$ in ethanol was used to infiltrate the cells $(1 \mathrm{~h})$ followed by $60 \%$ quetol $(1 \mathrm{~h})$ and lastly in $100 \%$ quetol $(4 \mathrm{~h})$. Specimen were embedded and polymerized $\left(60^{\circ} \mathrm{C}, 39 \mathrm{~h}\right)$. Ultra thin sections were prepared using a microtome and each section was mounted on a copper grid. Samples were contrasted in $4 \%$ aqueous uranyl acetate $(10 \mathrm{~min})$ and then in Reynolds lead citrate $(2 \mathrm{~min})$. To view the TEM images the JEM-2100F field emission transmission electron microscope (JEOL, Tokyo, Japan) was used. All Chemicals provided by the Electron Microscopy unit, University of Pretoria.

\section{Cell cycle progression}

Propidium iodide (PI) is a fluorescent dye used to quantify DNA content at $488 \mathrm{~nm}$ excitation [31]. Flow cytometry employing PI was used to distinguish cells in the different cell cycle phases. After exposure, cells were trypsinized and washed in $1 \mathrm{ml}$ ice-cold PBS and resuspended in $200 \mu \mathrm{l}$ ice-cold PBS. Cells were fixed in $4 \mathrm{ml}$ 
ice-cold $70 \%$ ethanol, added drop wise while vortexing and incubated overnight at $4{ }^{\circ} \mathrm{C}$. Cells were centrifuged (5 min at $100 \times g$ ) and the pellet resuspended in PBS containing $0.01 \%$ triton X-100, PI $(40 \mu \mathrm{g} / \mathrm{ml})$ and RNase A $(100 \mu \mathrm{g} / \mathrm{ml})$ and incubated for $40 \mathrm{~min}$ at $37^{\circ} \mathrm{C}$. PI fluorescence was measured using flow channel 3 (FL3) on the FC500 system flow cytometer (Beckman Coulter, California, USA) excited at $488 \mathrm{~nm}$. A minimum of 10,000 cells were analized using three biological repeats. Cell cycle distributions were analized with Cyflogic flow cytometry analysis software (Beckman Coulter, California, USA) using the DNA content per cell which illustrates the sub$G_{1}, G_{1}, S, G_{2} / M$ fractions.

\section{Apoptosis detection: annexin-V FITC}

Viable cells contain phosphatidylserine (PS), located on the inside of cell membrane. When apoptosis occurs, PS flip will occur. PS moves to the outside surface of cells to which annexin-V binds [32]. Washed cells were centrifuged and the supernatant discarded. The pellet was resuspended in annexin-V FITC binding buffer (0.25$10^{7}$ cells $\left./ \mathrm{ml}\right)$. Cell suspension $(100 \mu \mathrm{l})$ was pipetted into a $5 \mathrm{ml}$ test tube. Annexin-V FITC (5 $\mu \mathrm{l})$ and $10 \mu \mathrm{l}$ of PI was added and samples were incubated at room temperature (15 min) in the dark. After incubation $400 \mu \mathrm{l}$ annexin$\mathrm{V}$ binding buffer was added to each test tube. PI (FL3) and annexin-V (FL1) fluorescence was analyzed with the FC500 system flow cytometer (Beckman Coulter, California, USA) equipped with an air-cooled argon laser excited at $488 \mathrm{~nm}$. Three biological repeats with a minimum of 10,000 cells were analized. Data was analyzed with Cyflogic flow cytometry analysis software (Beckman Coulter, California, USA) with PI plotted on the $x$-axis and annexin V-FITC on the y-axis.

\section{Autophagy detection: microtubule-associated protein 1A/1B-light chain 3}

To detect autophagy, flow cytometry was used employing microtubule-associated protein 1A/1B-light chain 3 (LC3) using a conjugated rabbit polyclonal antiLC3B antibody which can be detected in FL1 (excitation $=488 \mathrm{~nm}$; emission $=525 \mathrm{~nm}$ ) [33]. After $24 \mathrm{~h}$ of exposure to ESE-15-ol with or without 3MA, washed trypsinized cells were resuspended in ice-cold PBS containing $0.01 \%$ formaldehyde and samples were incubated for $10 \mathrm{~min}$ at $4{ }^{\circ} \mathrm{C}$. Cells were centrifuged and resuspended in $200 \mu \mathrm{l}$ PBS to which $1 \mathrm{ml}$ ice-cold $100 \%$ methanol was added and incubated for $15 \mathrm{~min}$ at $4{ }^{\circ} \mathrm{C}$. Cells were washed twice with PBS. Cell pellet was resuspended in $200 \mu \mathrm{l}$ PBS containing $0.05 \%$ triton X-100, $1 \%$ BSA, $40 \mu \mathrm{g} / \mathrm{ml}$ PI and anti-LC3B/MAP1LC3B-antibody (1:200) (Novus Biological, Littleton, CO, USA) and incubated for $2 \mathrm{~h}$ at $4{ }^{\circ} \mathrm{C}$. Cells were washed twice with $1 \mathrm{ml}$
PBS containing $0.05 \%$ triton X-100 and 1\% BSA. LC3 fluorescence was measured in flow channel 1 (FL1) on the FC500 system flow cytometer (Beckman Coulter, California, USA). Three biological repeats with a minimum of 10,000 cells were used and data was analyzed with Cyflogic flow cytometry analysis software (Beckman Coulter, California, USA). Any cell debris and cell clumps were removed from analysis.

\section{Western blot analysis: LC3II}

After $24 \mathrm{~h}$ exposure, DMEM was aspirated and cells were washed with ice-cold PBS. $200 \mu \mathrm{l}$ RIPA cell lysis buffer $(150 \mathrm{mM} \mathrm{NaCl}, 0.1 \%$ SDS, $10 \mathrm{mM}$ Tris- $\mathrm{HCl}$ 0.5\% sodium deoxcylate, $1 \mathrm{mM}$ EGTA and $1 \mathrm{mM}$ EDTA in $\mathrm{ddH}_{2} 0$, adjusted to a $\mathrm{pH}$ of 7.4) was added to cells and incubated for $5 \mathrm{~min}$ on ice. Lysed cells were scraped and centrifuged for $30 \mathrm{~min}$ at $4{ }^{\circ} \mathrm{C}(1000 \times g)$. Protein concentration was determined by use of the Pierce ${ }^{\circledR}$ BCA protein assay kit (Thermo Fisher Scientific Inc., Rockford, Illinois, USA). In a 96 well plate, $20 \mu \mathrm{l}$ of the cytosolic extract was added to $100 \mu \mathrm{l}$ of the protein assay working solution. The absorbance was read at $570 \mathrm{~nm}$ by use of ELx800 Universal Microplate Reader (Bio-tek Instruments Inc. Vermont, USA). The protein concentration was calculated by using a standard curve. After protein quantification $25 \mu \mathrm{g}$ protein of each sample, containing $5 \% \mathrm{~b}$-mercaptoethanol and NuPAGE LDS buffer (1:4) (Sigma-Aldrich, St. Louis, USA) was denaturated at $96{ }^{\circ} \mathrm{C}$ (10 min). Samples $(20 \mu \mathrm{l})$ were loaded into NuPAGE $4-12 \%$ Bis-Tris gel wells alongside a relevant protein band size ladder. Samples were run in $1 \times$ MOPS buffer $(190 \mathrm{mM}$ Glycine, $25 \mathrm{mM}$ Tris and $0.1 \%$ SDS in $\mathrm{ddH}_{2} 0$, adjusted to a pH of 8.3 ) at $120 \mathrm{~V}$ for $90 \mathrm{~min}$ for protein separation via electrophoresis. Separated proteins were transferred to a PVDF $0.2 \mu \mathrm{m}$ membrane (Amersham Hybond, GE Healthcare Life Sciences) in $1 \times$ transfer buffer ( $48 \mathrm{mM}$ Tris, $39 \mathrm{mM}$ glycine, $20 \%$ methanol and $0.0375 \%$ SDS), which was activated with $100 \%$ methanol. Wet transfer was achieved overnight at $40 \mathrm{~V}$. After transfer, the membrane was blocked in $5 \mathrm{ml}$ blocking buffer (2\% BSA in $0.2 \%$ PBSTWEEN) for $30 \mathrm{~min}$ at room temperature. Membranes were incubated overnight at $4{ }^{\circ} \mathrm{C}$ in the primary antibody cocktail (1:1000 monoclonal LC3B/MAP1LC3B antibody produced in rabbit in 0.2\% PBS-Tween, $2 \%$ BSA) purchased from Novus Biological [Littleton, Colorado (CO), USA]. Membranes were washed three times in washing buffer for $15 \mathrm{~min}$ each. This was followed by $1 \mathrm{~h}$ incubation with the secondary antibody (anti-rabbit IgG antibody raised in goat labelled with horse-radish peroxidase (HRP) $(1: 10,000)$ (KPL, Mayland, USA) in $2.5 \%$ BSA in PBS. Membranes were washed three times in washing buffer for 15 min each. Pierce ${ }^{\circledR}$ ECL western blotting reagent (Thermo Fisher Scientific, MA, USA) was used to 
activate HRP activity to visualize proteins using ChemiDoc MP (Bio-Rad, CA, USA). Monoclonal anti-actin antibody produced in mouse (1:5000, Sigma-Aldrich, St. Louis, USA) was used to standardise the membranes and developed using the anti-mouse IgG secondary antibody raised in goat labelled with HRP (KPL, Mayland, USA). Image Lab 5.2.1 (Bio-Rad, CA, USA) was used to determine band size. Three biological repeats were done.

\section{Statistical analysis}

Morphology studies supplied qualitative data and crystal violet staining and flow cytometry analysis supplied quantitative data. Flow cytometry was repeated 3 times and involved the analysis of at least 10,000 cells per run. Three independent experiments were performed and data were shown as the mean \pm standard deviation. Analysis of variance (ANOVA) single factor model of significance was used to statistically analyze data and followed by a two-tailed Student's $t$-test. A statistical significant $P$ value of $<0.05$ was used and indicated with an asterisk (*) and (\#) was used to indicate a statistically significant difference between ESE-15-ol-exposed cells and those exposed in the presence of 3MA. Means are presented with bar-graphs with T-bars referring to standard deviations.

\section{Results}

Inhibition of autophagy decreases the cytotoxicity of ESE-15-ol as determined by spectrophotometry

Spectrophotometry was used to determine the effect of autophagy inhibition on the cytotoxicity of ESE-15ol-exposed human adenocarcinoma breast cancer cells (MCF-7) and metastatic human adenocarcinoma breast cancer cells (MDA-MB-231). The half maximum growth inhibitory concentrations $\left(\mathrm{IG}_{50}\right)$ of ESE-15-ol with and without 3MA were determined by dose-dependent studies over a $24 \mathrm{~h}$ period. The $\mathrm{IG}_{50}$ of ESE-15-ol was calculated at $0.05 \pm 0.018 \mu \mathrm{M}$ and at $0.15 \pm 0.014 \mu \mathrm{M}$ for ESE-15-ol with 3MA in MCF-7 cells (Fig. 2a). The $\mathrm{IG}_{50}$ of ESE-15-ol was calculated at $0.065 \pm 0.005 \mu \mathrm{M}$, and at $0.13 \pm 0.06 \mu \mathrm{M}$ for ESE-15-ol with 3MA-exposed MDAMB-231 cells (Fig. 2b). Autophagy inhibition was thus seen to have caused a statistically significant decrease in ESE-15-ol cytotoxicity, with a $P$ value of 0.007 in MCF-7 cells and 0.0195 in MDA-MB-231 cells.

\section{Morphological features of cell death induced by ESE-15-ol were atteniated by addition of 3MA}

Polarization-optical transmitted light differential interference light microscopy (PlasDIC) was used to evaluate the morphological response of cells to ESE-15-ol with or without 3MA. MCF-7 (Fig. 3ai) and MDA-MB-231 (Fig. 3aii) cells exposed to DMSO showed no signs of cell distress. Confluent cell growth was seen with visible nucleoli as for the 3MA-exposed cells (Fig. 3bi, bii). Cells were mostly present in interphase. Actinomycin D-treated cells showed a decrease in cell density for both MCF-7 (Fig. 3ci) and MDA-MB-231 (Fig. 3cii) cells. Apoptotic body formation, cell debris and shrunken cells were visible, which are characteristic of apoptotic cell death. ESE-15-ol-treated MCF-7 (Fig. 3di) and MDAMB-231 (Fig. 3dii) cells demonstrated an increased proportion of rounded cells as well as the presence of apoptotic bodies. ESE-15-ol-treated cells together with 3MA showed apoptotic body formation and rounded cells in both MCF-7 (Fig. 3ei) and MDA-MB-231 cells (Fig. 3eii), but to a lesser extend when compared to cells treated with ESE-15-ol without 3MA.

\section{Acidic vacuoles were decreased in cells treated with ESE-15-ol in combination with 3MA}

Monodansylcadaverine (MDC) is a weak base fluorescent stain which stains acidic vacuoles that suggest occurence of autophagy [34]. MCF-7 and MDA-MB-231 cells exposed to DMSO (Fig. 4ai, aii) and 3MA (Fig. 4bi, bii) showed non-specific MDC staining. Both controls displayed confluent cell growth. Tamoxifen-treated cells (Fig. 4ci, cii) showed an increase in MDC-stained vacuoles in both cell lines. ESE-15-ol-treated cells demonstrated an increase in MDC-stained vacuoles, as well as decreased cell density (Fig. 4di, dii). ESE-15-ol treated cells in the presence of 3MA showed a decrease in MDC staining, with less acidic vacuole formation apparent when compared to the drug treated sample (Fig. 4ei, eii).

\section{Vacuole formation in response to ESE-15-ol exposure was} evident but diminshed when co-incubated with $3 M A$

Transmission electron microscopy was used to analyze the ultrastructure of ESE-15-ol-treated MCF-7 and MDA-MB-231 cells, with and without autophagy inhibition by 3MA. Cells propagated in DMSO (Figs. 5a, 6a) showed a smooth cell membrane with minimal cellular protrusions, together with an intact nuclear envelope. No morphological differences were seen between cells exposed to DMSO and 3MA (Figs. 5b, 6b). Cells treated with actinomycin D (Figs. 5c, 6c) increased membrane blebbing and apoptotic body formation representative of apoptotic cell death. Tamoxifen-treated cells showed an increase in vesicle formation (Figs. 5d, 6d). Less vacuole formation was observed in tamoxifen-treated cells with 3MA (Figs. 5e, 6e). This suggests partial autophagy inhibition by 3MA. Intact cell membranes were observed in tamoxifen-treated cells, with and without 3MA. ESE15-ol-treated cells (Figs. 5f, 6f) displayed an increase in vacuolar structures indicative of autophagy. Apoptotic bodies, hypercondensed chromatin and increased cell 

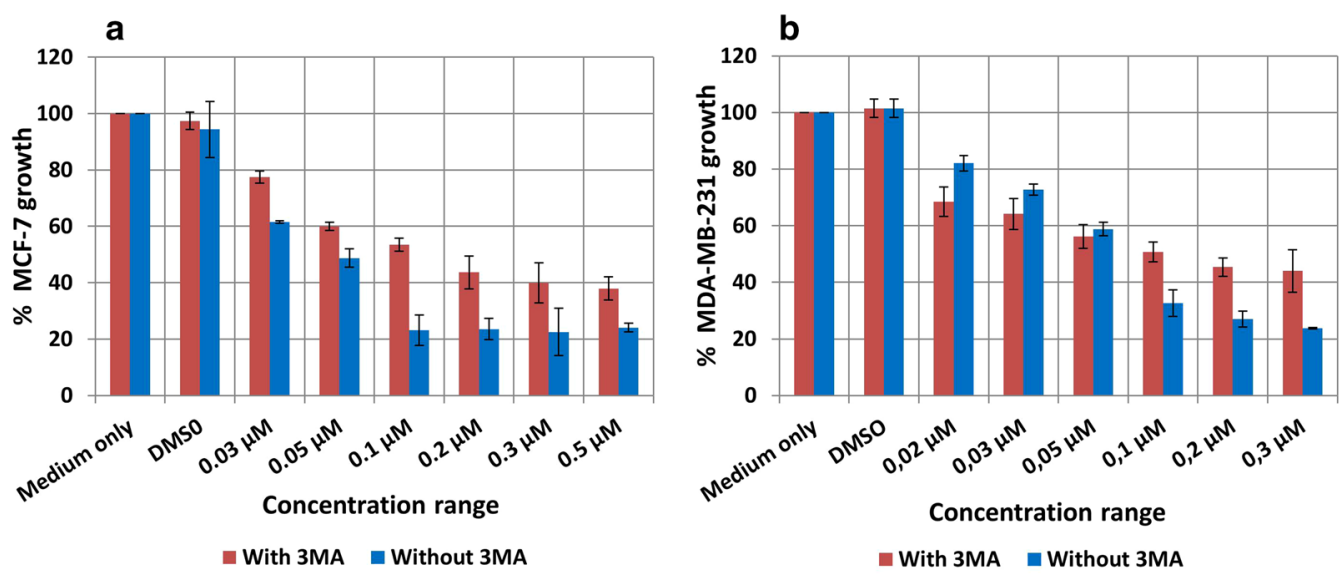

Fig. 2 Cytotoxicity study for ESE-15-ol with/without 3MA over a $24 \mathrm{~h}$ exposure period in MCF-7 and MDA-MB-231 breast cancer cells. a The dose dependent curve for MCF-7 cells showed an IG ${ }_{50}$ of $0.15 \mu \mathrm{M}$ for ESE-15-ol with 3MA and $0.05 \mu \mathrm{M}$ for ESE-15-ol only (P-value =0.007); b MDAMB-231 cells showed an $\mathrm{IG}_{50}$ of $0.13 \mu \mathrm{M}$ for ESE-15-ol with $3 \mathrm{MA}$ and $0.065 \mu \mathrm{M}$ for ESE-15-ol only ( $P$-value $=0.0195$ ). Bars indicate averages of three independent biological repeats, each with $n=3$. Error bars represent standard deviation

protrusions were also observed in cells exposed to ESE15-ol. ESE-15-ol-treated cells with 3MA inhibition of autophagy (Figs. 5g, 6g) revealed cells with intact nuclearand cell-membranes. A decrease in cellular distress with fewer vesicles was observed in these cells.

\section{MA co-incubation increased cell viability and reduced $G_{2} / M$ block as well as the sub- $G_{1}$ population in response to ESE-15-ol exposure}

The quantification of cells at various stages within the cell cycle was determined with flow cytometry. Cell cycle distribution of MCF-7 cells exposed to DMSO (Fig. 7ai) showed an average of $3.24 \pm 0.54 \%$ in the sub- $\mathrm{G}_{1}$ phase, $56.2 \pm 4.89 \%$ in the $G_{1}$ phase and $18.79 \pm 0.89 \%$ in the $\mathrm{G}_{2} / \mathrm{M}$ phase. Cell cycle distribution of MDA-MB-231 cells grown in DMSO (Fig. 7aii) showed an average of $2.53 \pm 1.62 \%$ in the sub- $\mathrm{G}_{1}$ phase, $57.8 \pm 0.61 \%$ in the $G_{1}$ phase and $29.5 \pm 1.83 \%$ in the $G_{2} / M$ phase. No statistical significance was found between cells grown in medium only and treated with DMSO or 3MA, indicating that the vehicle was non-toxic to the cells. MCF-7 and MDA-MB-231 cells exposed to actinomycin D and ESE-15-ol had statistically significant changes in their cell cycle distributions when compared to the
DMSO vehicle control. Actinomycin D-treated MCF-7 cells (Fig. 7bi) had a significant increase in the sub$G_{1}$ phase $(9.47 \pm 0.31 \% ; P=0.00015)$ and the $G_{2} / M$ $(22.98 \pm 2.32 \% ; P=0.04)$ phase. ESE-15-ol-treated MCF-7 cells (Fig. 7ci) had a significant increase in the sub- $\mathrm{G}_{1}$ phase $(18.14 \pm 2.81 \% ; P=0.001)$ and the $\mathrm{G}_{2} / \mathrm{M}$ phase $(60.28 \pm 1.34 \% ; P=0.0009)$ when compared to the DMSO control. ESE-15-ol-treated MCF-7 cells together with 3MA autophagy inhibition (Fig. 7di) had a statistically significant increase in the $\mathrm{G}_{1}$ phase $(35.70 \pm 7.45 \%$; $P=0.02)$ when compared to ESE-15-ol without 3MA treatment $(13.59 \pm 0.36 \%)$. Actinomycin D treated MDAMB-231 cells (Fig. 7bii) had a significant decrease in the $\mathrm{G}_{1}$ phase $(31.94 \pm 2.75 \% ; P=0.0004)$ and concomitant increase in the $\mathrm{G}_{2} / \mathrm{M}$ phase $(48.52 \pm 2.63 \% ; P=0.02)$ when compared to DMSO-exposed cells. ESE-15-oltreated MDA-MB-231 cells (Fig. 7cii) had a significant decrease in the $\mathrm{G}_{1}$ phase ( $\left.44.45 \pm 1.59 \% ; P=0.008\right)$ with a significant increase in the $\mathrm{G}_{2} / \mathrm{M}$ phase $(43.23 \pm 2.13 \%$; $P=0.009$ ) when compared to DMSO vehicle control. ESE-15-ol-treated MDA-MB-231 cells with a concurrent treatment with 3MA (Fig. 7dii) had a statistically significant increase in the $\mathrm{G}_{1}$ phase $(63.64 \pm 4.46 \%$; $P$ 0.03) when compared to cells exposed to ESE-15-ol without

(See figure on next page.)

Fig. 3 PlasDIC images of MCF-7 and MDA-MB-231 cells exposed to the compound with/or without 3MA for $24 \mathrm{~h}$. i MCF-7 cells and ii MDA-MB-231 cells grown in a DMSO and $\mathbf{b} 3 \mathrm{MA}$ served as negative controls. Confluent cell growth with no signs of cell distress was demonstrated. $\mathbf{c}$ Actinomycin $D(0.1 \mu \mathrm{g} / \mathrm{ml})$ served as a positive control for apoptosis, resulting in apoptotic body formation and compromised cell density. d ESE-15-oltreated cells revealed the presence of rounded cells, formation of apoptotic bodies and decreased cell density. e ESE-15-ol exposure to cells in which autophagy had been inhibited with 3MA showed an increase in cell viability. (Arrow colour key: Yellow = interphase cells; orange = rounded cells in metaphase; white $=$ apoptotic bodies.) 


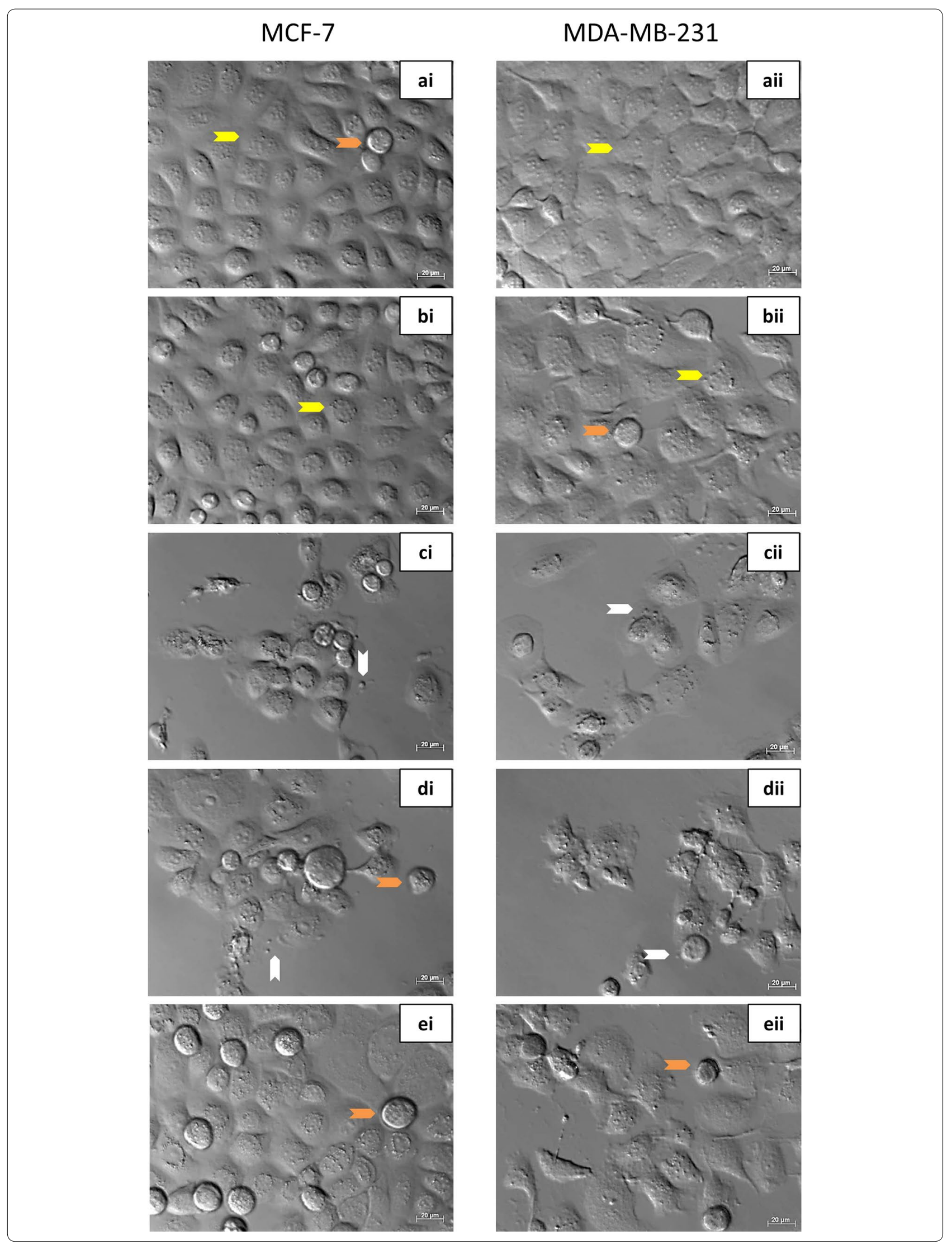




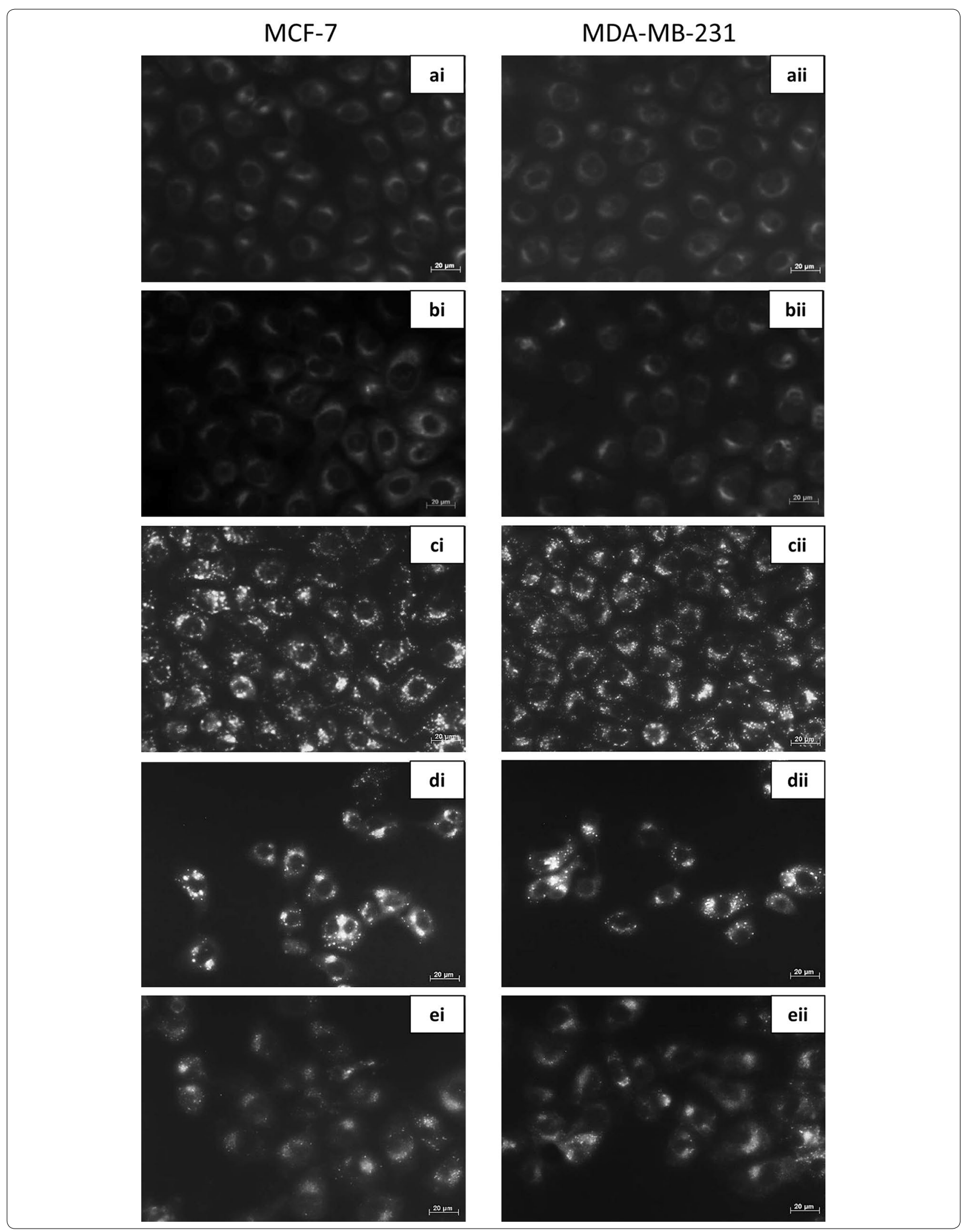


(See figure on previous page.)

Fig. 4 Fluorescent microscopy with monodansylcadaverine staining of MCF-7 and MDA-MB-231 cells. i MCF-7 and ii MDA-MB-231 cells treated with a DMSO and $\mathbf{b} 3$ MA served as negative controls and displayed non-specific MDC staining. c Tamoxifen was used as a positive control for acidic vacuoles and displayed clear MDC stained vacuoles. d ESE-15-ol treated cells showed increased MDC staining, while e ESE-15-ol treated cells together with 3MA showed less distinctive MDC staining, indicating partial autophagy inhibition (40× magnification)

3MA. These results indicate that autophagy inhibition decreases the cytotoxic effect of ESE-15-ol exposure in MCF-7 and MDA-MB-231 breast cancer cells.

\section{Apoptosis induction in response to ESE-15-ol was diminshed with addition of 3MA}

Flow cytometry employing annexin V-FITC and PI was used to distinguish between viable-, apoptotic- and necrotic cells. Statistical analysis of dot plots data indicated a statistically significant increase in apoptosis in actinomycin D-treated (Fig. 8bi) (40.06 \pm 5.55\%; $P=0.001$ ) and ESE-15-ol-treated (Fig. 8ci) (21.21 $\pm 0.13 \% ; P=0.002)$ MCF-7 cells when compared to the DMSO-vehicle control (Fig. 8ai). A statistically significant increase in apoptosis in actinomycin D-treated (Fig. 8bii) (25.39 $\pm 3.44 \% ; P=0.0006)$ and ESE-15ol-treated (Fig. 8cii) MDA-MB-231 cells (38 $\pm 7.02 \%$; $P=0.004)$ was detected when compared to the DMSOvehicle control (Fig. 8aii). No statistically significant difference in viability was detected between cells grown in medium only, DMSO-exposure and 3MA-exposure in both MCF-7 and MDA-MB-231 cells. A statistically significant increase in viability in ESE-15-ol-treated MCF-7 and MDA-MB-231 cells together with 3MA $(81.31 \pm 2.05 \% ; P=0.01$ and $83.97 \pm 5.6 \% ; P=0.01$, respectively) was observed when compared to ESE-15-oltreated cells (Fig. 8ei, eii).

LC3 expression was increased in cells exposed to ESE-15-ol Flow cytometry employing a microtubule-associated protein 1A/1B-light chain 3 (LC3) conjugated rabbit polyclonal anti-LC3B antibody (Novus Biologicals, Littleton, $\mathrm{CO}$ ) was used to quantify and confirm induction and inhibition of autophagy. Figure 9a illustrates an overlay histogram of MCF-7 (1) and MDA-MB-231(2) cells exposed to ESE-15-ol with and without 3MA. A right shift is seen in ESE-15-ol-treated cells without 3MA. A decrease in LC3 detection is seen in cells

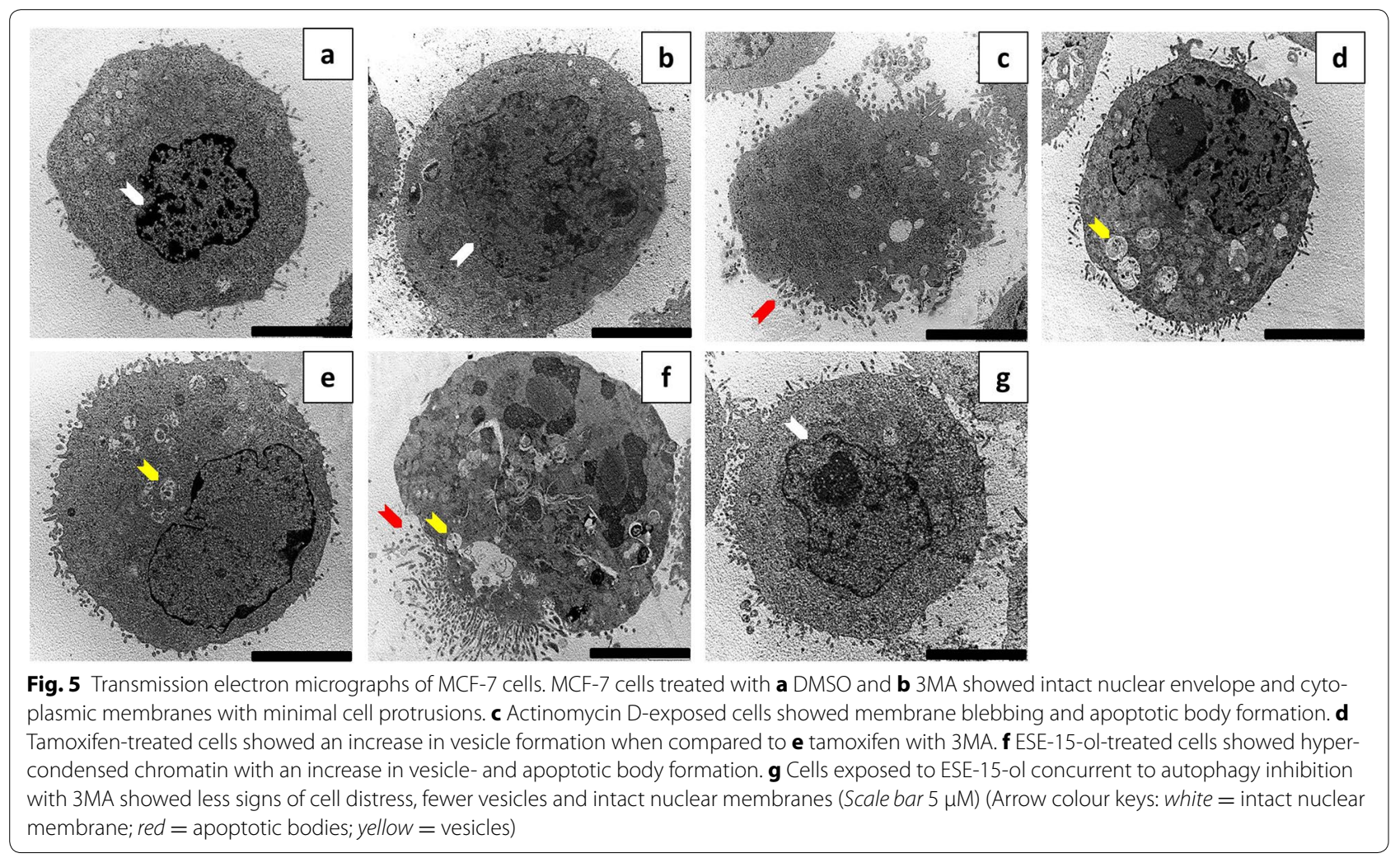



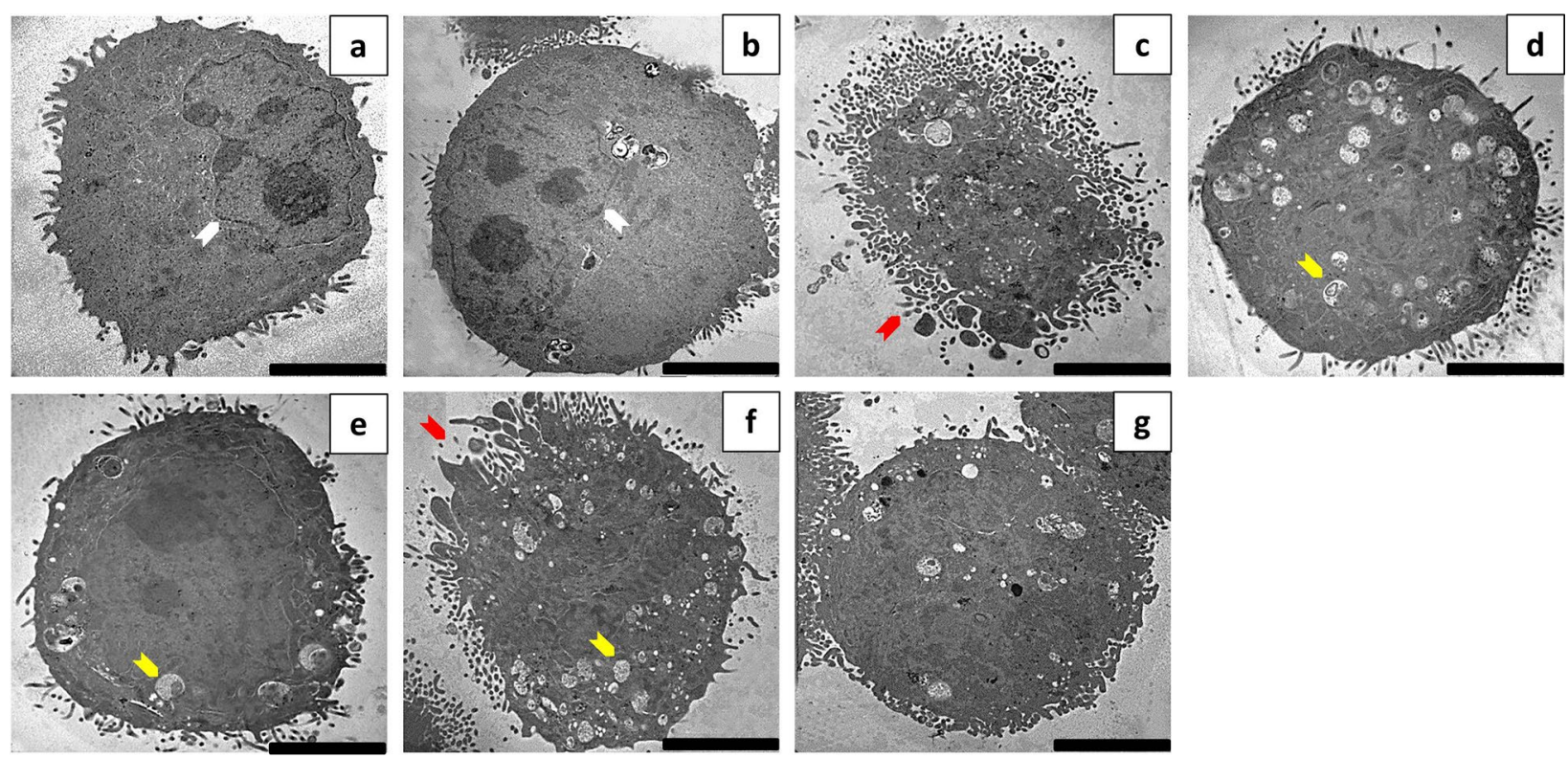

Fig. 6 Transmission electron micrographs of MDA-MB-231 cells. MDA-MB-231 cells treated with a DMSO and $\mathbf{b} 3$ MA showed an intact nuclear membrane and well-defined cell membranes with minimal cell protrusions. c Actinomycin D-exposed cells showed membrane blebbing and apoptotic body formation. $\mathbf{d}$ Tamoxifen-treated cells showed more vesicle formation when compared to cells treated with e tamoxifen with $3 \mathrm{MA}$. f ESE-15-ol-treated cells showed hyper condensed chromatin with increased vesicles and apoptotic body formation. $\mathbf{g}$ Cells exposed to ESE-

15-ol with 3MA showed fewer vesicles with an intact nuclear membrane (Scale bar $5 \mu \mathrm{M}$ ) (Arrow colour keys: white = intact nuclear membrane; red $=$ apoptotic bodies; yellow $=$ vesicles)

exposed to ESE-15-ol together with 3MA indicating partial autophagy inhibition. No difference was detected between cells grown in medium only and cells exposed to the DMSO vehicle control and 3MA (not shown in overlay). Graphical representations in Fig. 9b show a statistically significant fold increase of $2.075 \pm 0.05$ LC3 after tamoxifen exposure and $1.67 \pm 0.17$ LC3 in ESE15-ol when compared to the DMSO vehicle control. A statistically significant fold decrease of LC3 is seen after tamoxifen with 3MA exposure $(1.40 \pm 0.25 ; P=0.022)$ when compared to tamoxifen exposure alone, as well as between ESE-15-ol with 3MA $(1.13 \pm 0.11 ; P=0.004)$ when compared to ESE-15-ol alone.

\section{LC3I conversion to LC3II decreased in cells treated with ESE-15-ol together with 3MA}

LC3II has a role in cytoplasmic cargo selection, autophagosome membrane tethering and fusion [35]. Increased levels of LC3-II may be associated with an upregulation in autophagy or a decrease in turnover (altered autophagic flux). Western blots were used to quantify the formation of LC3II in the presence of the analogue with- and without 3MA (Fig. 10). Protein quantification revealed a statistically significant fold-increase in LC3II expression when MCF-7 cells were exposed to ESE15 -ol (1.23 $\pm 0.11, P=0.02)$ and tamoxifen $(2.55 \pm 0.35$, $P=0.003$, as did the MDA-MB-231 cells $(2.75 \pm 0.35$,
$P=0.002$ and $2.4 \pm 0.42, P=0.004$ respectively), when compared to the DMSO control. Addition of 3MA reduced LC3II expression to $0.73 \pm 0.09$-fold (MCF-7 cells) and to $1.4 \pm 0.56$ (MDA-MB-231 cells), statistically significant when compared to ESE-15-ol only-exposed MCF-7 $(P=0.015)$ and MDA-MB-231 cells $(P=0.04)$ respectively. Similar trends were seen in the tamoxifentreated positive control samples.

\section{Discussion}

$2 \mathrm{ME}$ is an anti-proliferative agent which shows promise in cancer treatment, including breast cancer [36]. It induces both the intrinsic- and extrinsic apoptotic pathways through inactivation of $\mathrm{Bcl}-2$ and increased DR5 expression [5]. Several promising analogues of 2ME, such as 2-methoxyestradiol-bis-sulfamate (2MEOE2bisMATE) have been developed for improved potency and bioavailability of the parent drug $[9,36,37]$. Our laboratory has in silico-designed a range of sulphamoylated estrone analogues with the added intention to localise them to solid tumour micromilieus through an increased CAIX binding affinity $[9,38]$.

Of these compounds, ESE-15-ol, 2-ethyl-3-O-sulphamoyl-etsra-1,3,5 (10) 15-tetraene-3-ol-17-one (ESE15-one) and 2-ethyl-3-O-sulphamoyl-etsra-1,3,5 (10) 16-tetraene (ESE-16) have been investigated for modes of cell death induction (apoptosis and autophagy) on 


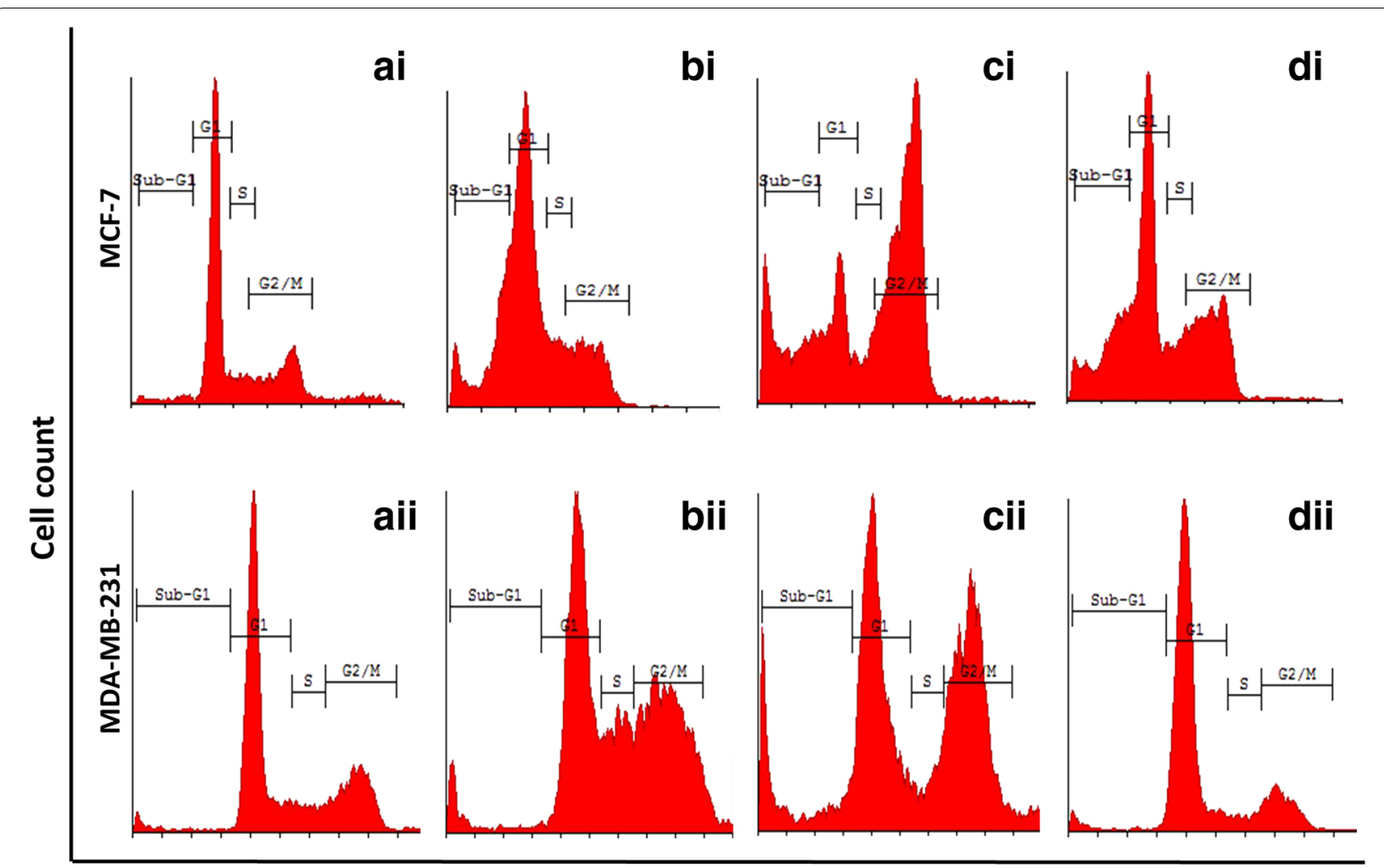

DNA (PI) FL3 lin
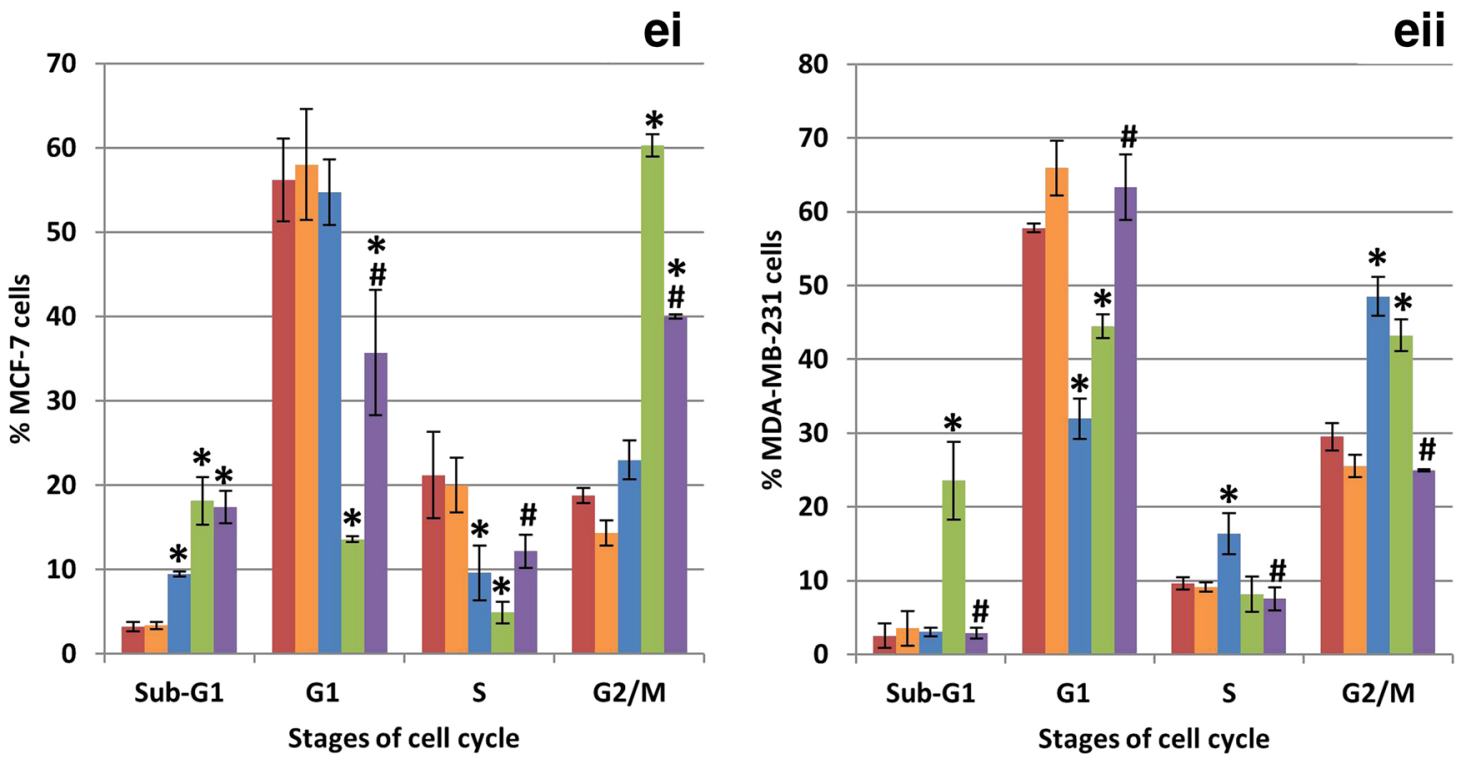

DMSO

3MA

Actinomycin D

ESE-15-ol

ESE-15-ol + 3MA

Fig. 7 Cell cycle analysis of MCF-7 and MDA-MB231 cells exposed to ESE-15-ol with- and without 3MA. Cells were exposed to DMSO as a negative vehicle control (ai, aii) which showed a prominent $G_{1}$ phase. Actinomycin $D(\mathbf{b i}$, bii) was used as a positive control for apoptosis which resulted in an increase in the sub- $\mathrm{G}_{1}$ phase. An increase in the $\mathrm{G}_{2} / \mathrm{M}$ phase was seen in ESE-15-ol-treated cells (ci, cii) with a concurrent decrease in the $\mathrm{G}_{1}$ phase. ESE-15-ol treated cells together with $3 \mathrm{MA}$ (di, dii) showed a decrease in the $\mathrm{G}_{2} / \mathrm{M}$ phase with an increase in the $\mathrm{G}_{1}$ phase. Graphical representation of ei MCF-7 and eii MDA-MB-231 cell cycle analysis. ESE-15-ol-treated cells together with 3 MA demonstrated an increase in the $G_{1}$ phase when compared to ESE-15-ol-treated cells ( $P$ value $<0.05$; standard deviation represented by T-bars; ${ }^{*}$ indicates statistical difference between compounds and DMSO vehicle control; " indicates statistical difference between ESE-15-ol and ESE-15-ol with 3MA) 


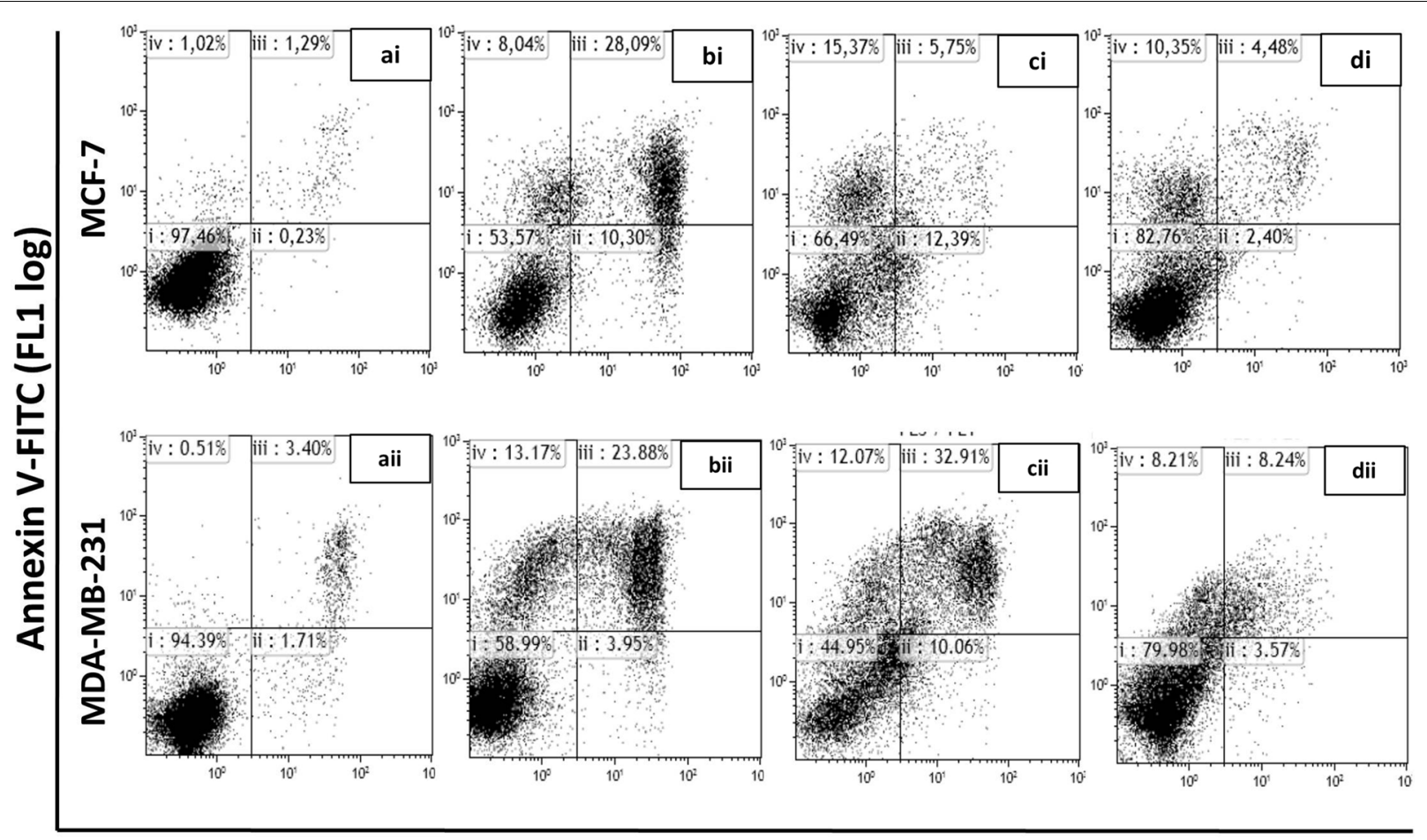

Propidium lodide (FL3 log)
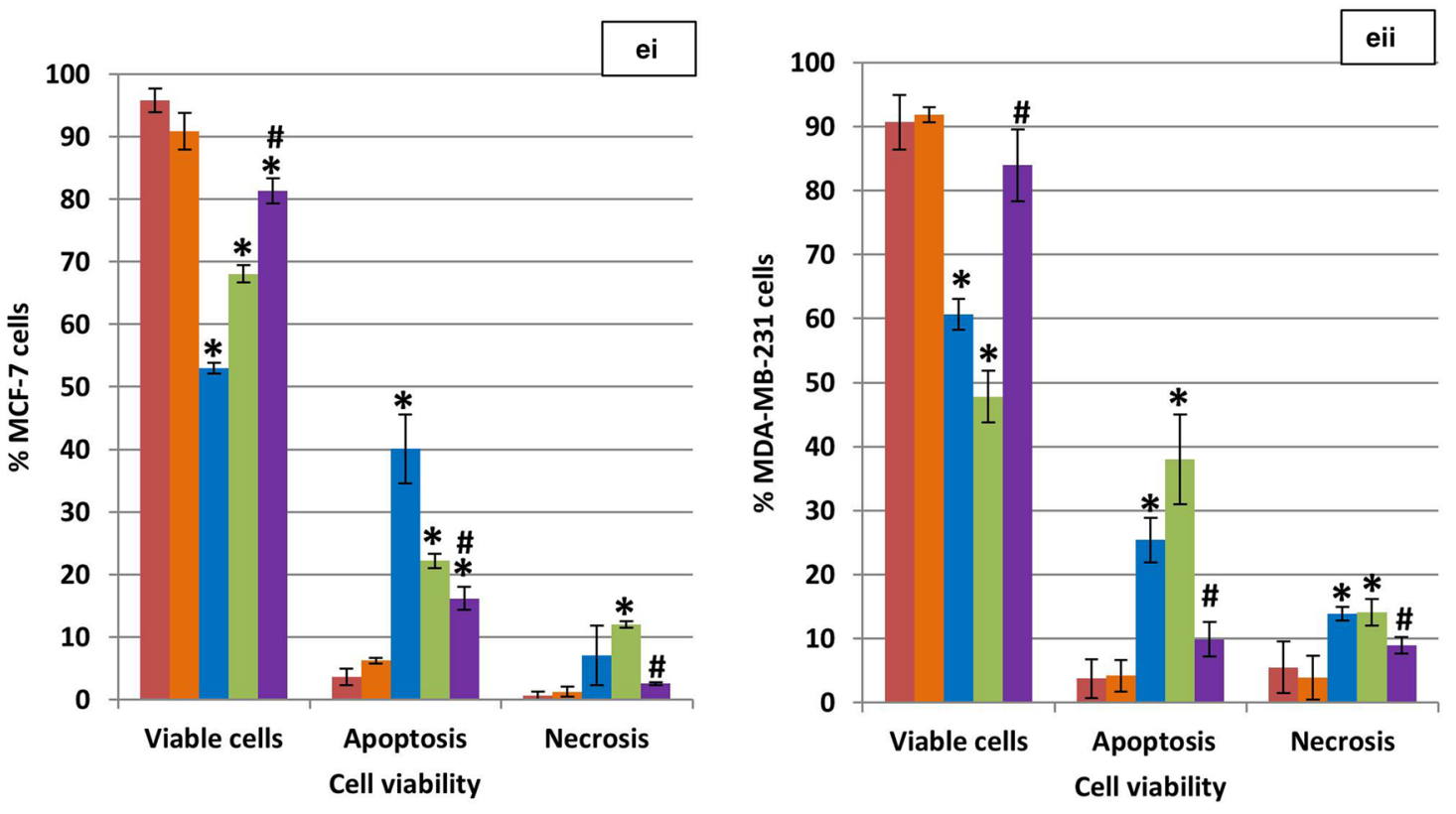

DMSO

3MA

Actinomycin D

ESE-15-ol

ESE-15-ol + 3MA

Fig. 8 Annexin-V FITC flow cytometric analysis of cell viability. Dot blots of $\mathbf{i}$ MCF-7 and ii MDA-MB-231 cells exposed to a DMSO as a vehicle control and demonstrated a viable cell population. Dot blots of $\mathbf{b}$ actinomycin D (positive apoptosis control) and $\mathbf{c}$ ESE-15-ol-treated cells showed increased cell death via apoptosis. d ESE-15-ol-treated cells with 3MA showed increased cell viability when compared to cells exposed to ESE-15-0l only. Graphical representation of (ei) MCF-7 and (eii) MDA-MB-231 cells showed a decrease in cell viability in cells treated with ESE-15-ol when compared to DMSO. An increase in viable cells is observed in ESE-15-ol treated cells with 3MA when compared to ESE-15-ol treated cells. Bars represent averages of three biological repeats ( $P$ value $<0.05$; standard deviations represented by $T$-bars; ${ }^{*}$ indicates statistical difference between compounds and DMSO vehicle control; \#indicates statistical difference between ESE-15-ol and ESE-15-ol with 3MA) (Dot plot keys: $\mathbf{i}=$ viable cells; $\mathbf{i i}=$ necrosis; iii = late apoptosis; iv early apoptosis) 
MCF-7

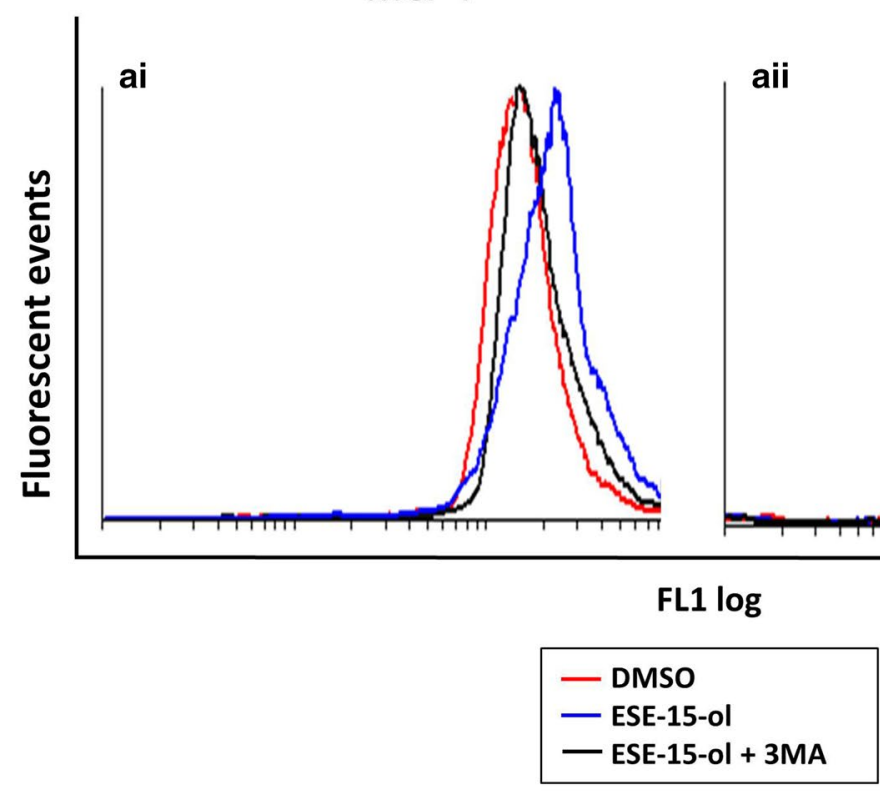

b

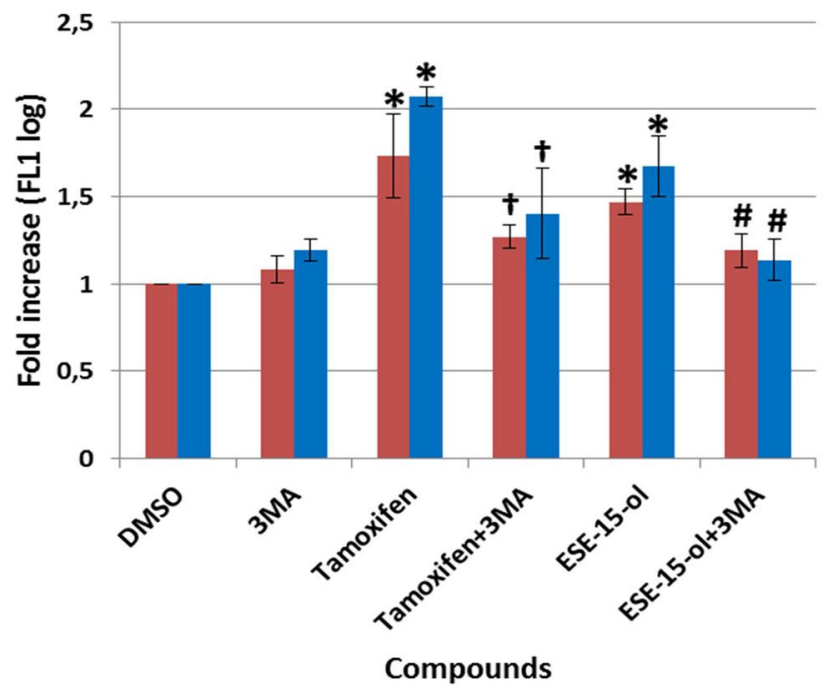

- MCF-7

MDA-MB-231

Fig. 9 LC3 fluorescence determination within MCF-7 and MDA-MB-231 cells after a $24 \mathrm{~h}$ exposure. Overlay histogram of ai MCF-7 and aii MDAMB-231 exposed cells. Cells treated with ESE-15-ol showed a right shift which was greater than ESE-15-ol with 3MA. b Graphical representation shows an increase in LC3 detection within ESE-15-ol-treated cells. Bars represent averages of three biological repeats $(P$ value $<0.05$; standard deviations represented by T-bars; ${ }^{*}$ indicates statistical differences between compounds and DMSO vehicle control; ${ }^{*}$ indicates statistical difference between ESE-15-ol and ESE-15-ol with 3MA; ${ }^{\dagger}$ indicates statistical difference between tamoxifen and tamoxifen with 3MA)

various cancer cell lines $[9,36,39-41]$. Authors have indicated the increased presence of autophagic vesicles at certain time points after drug exposure [42]. Extensive analysis of the drug's effect on induction or flux of autophagy have not been completed, although up-regulation of autophagic genes have been reported on microarrays [42]. Descriptions of autophagy conceptualize a dual role within the context of cellular survival, either inducing programmed cell death type II or activating a pro-survival phenotype [19]. Autophagy can be activated by tumor microenvironments to protect hypoxic and nutrient deprived cells, thus inducing resistance to drug treatment [43]. The current study aimed to determine the role of autophagy associated demonstrated on cancer cell exposure to ESE-15-ol by inhibiting autophagy with 3MA. 


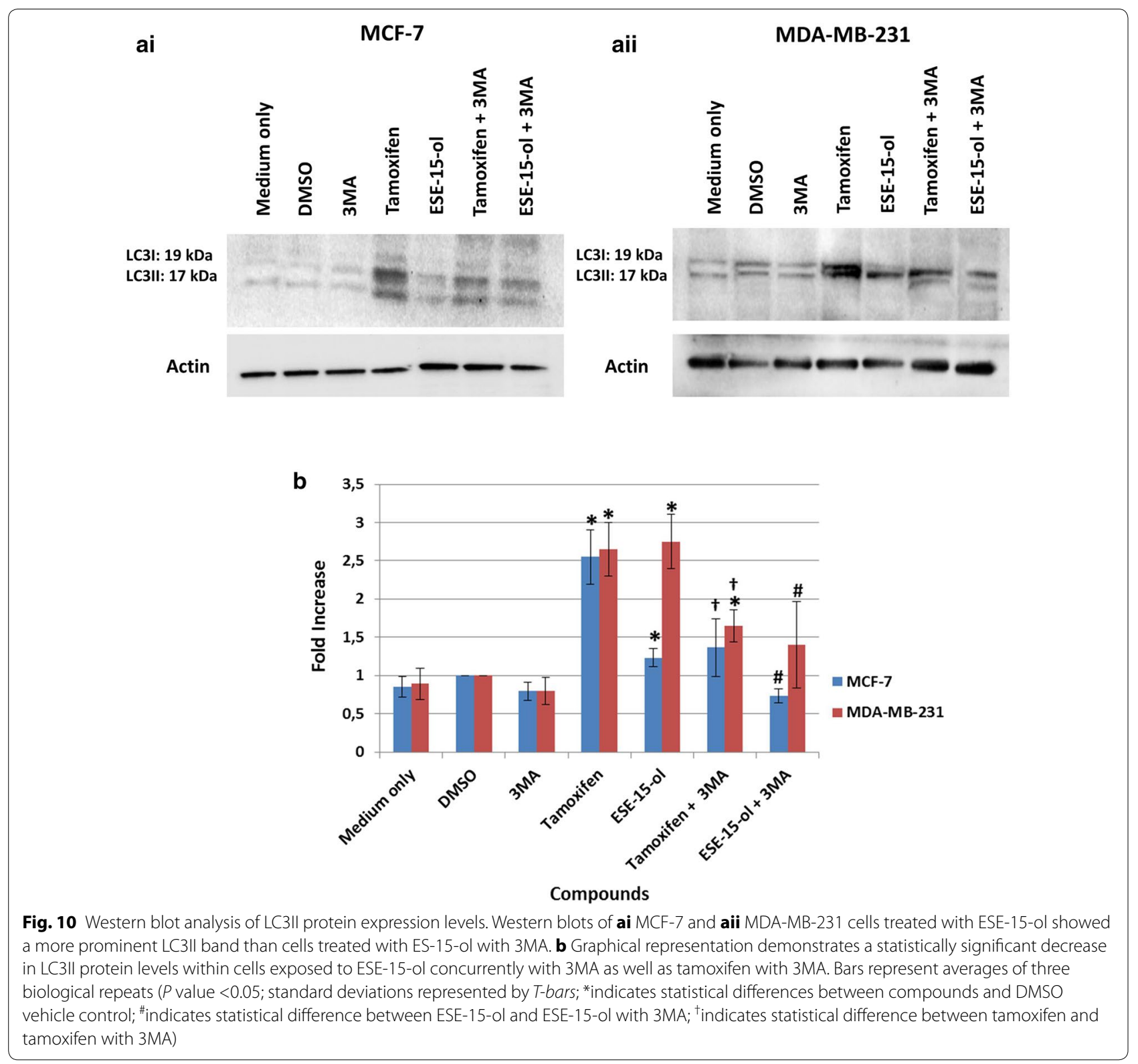

Cytotoxicity studies on MCF-7 and MDA-MB-231 breast adenocarcinoma cells were conducted over a $24 \mathrm{~h}$ period by spectrophotometric quantification of crystal violet. $\mathrm{IG}_{50}$ values were determined for ESE-15-oltreated cells, and compared to the value obtained when 5 mM 3MA, an inhibitor of autophagy, was added for the duration of the drug exposure. This was done to determine the effect which autophagy inhibition would have on the cytotoxicity of ESE-15-ol on MCF-7 and MDAMB-231 cells. IG $_{50}$ values of 0.05 and $0.065 \mu \mathrm{M}$ were calculated for MCF-7 and MDA-MB-231 cells respectively when exposed to ESE-15-ol without $3 \mathrm{MA}$. $\mathrm{IG}_{50}$ values of 0.15 and $0.1 \mu \mathrm{M}$ in MCF-7 and MDA-MB-231 cells respectively were determined for ESE-15-ol together with $3 \mathrm{MA}$. The increase in $\mathrm{IG}_{50}$ values with the addition of 3MA were statistically significant in both cell lines $(P=0.007 ; P=0.0195)$. ESE-15-ol without $3 \mathrm{MA}$ had an increased cytotoxicity than with $3 \mathrm{MA}$. The results indicate the possibility that autophagy contributes to the cell death process in cells exposed to ESE-15-ol.

Various microscopic techniques were used to determine the effect of autophagy inhibition on the morphology of MCF-7 and MDA-MB-231 cells after ESE-15-ol-exposure. PlasDIC microscopy revealed that ESE-15-ol-exposure resulted in numerous rounded cells, most likely in mitotic arrest, supporting its action 
as a spindle poison. Cell cycle analysis corroborated this induction due to an increase in cells present in the $G_{2} / M$ phase. Previous studies have reported that a mitotic block was caused in MCF-7 cells exposed to $1 \mu \mathrm{M} 2 \mathrm{ME}$, the parent compound of ESE-15-ol [5]. Apoptotic bodies and shrunken cells were visualized on the micrographs of ESE-15-ol-exposed cells. This suggests that ESE15-ol induced cell death via apoptosis over a $24 \mathrm{~h}$ exposure period due to spindle disruption. Theron et al. [11] showed that ESE-16-ol and ESE-15-one induced metaphase block due to abrogation of microtubule dynamics and non-satisfaction of the spindle assembly checkpoint (SAC), thereby inducing apoptosis in MDA-MB-231 and HeLa cells. In this study, only a small proportion of cells demonstrated a mitotic arrest, although apoptotic bodies were still visible when cells were treated with ESE-15-ol combined with 3MA (an effect which was more subtle when compared to cells exposed to the compound-only). Thus signs of apoptotic cell death were still present when autophagy was inhibited. For optimal cell death by ESE15-ol both apoptosis and autophagy are hypothesized to be involved.

Fluorescent microscopy employing MDC was used to detect acidic vacuoles that may be indicative of autophagy. MCF-7 and MDA-MB-231 cells treated with ESE-15-ol over a $24 \mathrm{~h}$ period showed positive staining for MDC, with more discrete vacuolar formation. Cells treated with ESE-15-ol in combination with 3MA showed a decrease in MDC staining when compared to cells treated with ESE-15-ol alone. This indicates that 3MA blocked autophagy induced by ESE-15-ol, albeit incompletely. TEM was conducted to investigate the effects of ESE-15-ol as well as, autophagy inhibition on the ultrastructure of MCF-7 and MDA-MB-231 cells. Cells exposed to ESE-15-ol and tamoxifen (positive control) showed an increased number of vacuoles which are indicative autophagic vacuoles. Apoptotic bodies were observed in ESE-15-ol-treated cells, together with cellular distress, chromatin hypercondensation and membrane blebbing, indicating cell death via apoptosis. Cells exposed to ESE-15-ol together with 3MA demonstrated significantly less distress and a decrease in vacuole formation.

Apoptotic characteristics observed in the morphology studies of the drug-exposed cells were quantified using flow cytometry. Analysis of cell cycle progression showed a statistically significant decrease in mitotic arrest when MCF-7 and MDA-MB-231 cells were treated with ESE15-ol with 3MA when compared to ESE-15-ol without $3 \mathrm{MA}$. A statistically significant increase in the $\mathrm{G}_{1}$ phase was also demonstrated when cells were treated with ESE15-ol with 3MA when compared to ESE-15-ol without 3MA. Quantification of the translocation of PS to the outer membrane of the cell during apoptosis was also done by flow cytometry. ESE-15-ol-exposed cells showed an increase in apoptosis to $21.21 \%$ for MCF-7 cells and $38 \%$ for MDA-MB-231 cells with a decrease in cell viability. Autophagy inhibition demonstrated a decrease in apoptosis (16.13\% for MCF-7 cells and 6.74\% for MDAMB-231 cells). This suggests that 3MA increased cell viability when combined with ESE-15-ol.

Flow cytometry studies employing LC3 detection were used to quantify the presence of autophagic vacuoles. MCF-7 and MDA-MB-231 cells treated with ESE15-ol showed a significant fold increase in LC3 detection when compared to the DMSO vehicle control. Additionally, 3MA inhibition of autophagy were quantified and verified in tamoxifen-treated cells. The decrease of acidic vacuoles seen with MDC staining of ESE-15-ol treated cells with 3MA as well as the TEM findings were corroborated by the decrease in LC3 detection via flow cytometry. These results verified that $3 \mathrm{MA}$ incompletely blocked autophagy. LC3 is a marker for autophagic induction or to detect a decrease in autophagosome formation, but does however, have limitations. There are multiple isoforms of LC3 (LC3A, LC3B, LC3B2 and LC3C), as well as variation in the antibody specificity (LC3I vs LC3II). ATG8-PE/LC3II is a protein marker which detects completed autophagosome formation but does not measure or quantify autophagy flux (flow cytometry indicative of total LC3 levels and does not differentiate between LC3I and LC3II). Autophagic flux is often quantified via LC3II turnover as detected by Western blotting [44]. When co-incubated with the autophagy inhibitor 3MA, the decreased LC3II expression in comparison to the elevated expression induced by ESE-15-ol, alludes to a disruption in autophagic flux, although these results must be interpreted with cauation due to the analytic constraints of autophagy quantification. This study indicated that the drug treatment did increase the LC3II expression, a response which was muted by co-incubation with 3MA.

Autophagosomes are transported to the microtubuleorganising centre (MTOC) of cells along the microtubules where lysosome cluster are found [45]. In the MTOC, lysosome fusion and content exchange occurs after which autophagosomal degradation by lysosomal hydrolases take place [45]. It is hypothesised that ESE-15-ol increases the induction of autophagy, possibly by the increased formation of reactive oxygen species [6]. Microarray analysis of autophagy gene expression indicated up-regulation of autophagy-related genes after exposure to 17-beta estradiol analogues [42]. However, ESE-15-ol disrupts microtubule dynamics which are essential for autophagy, potentially retracting autophagosome fusion and degradation. A possible explanation for the induction of 
autophagy by ESE-15-ol could be the inhibition of beclin-1. 3MA can possibly increase beclin-1 expression causing autophagy inhibition. These results support previous studies done with estradiol analogues and 2ME that indicate a molecular crosstalk between apoptosis and autophagy [36]. In addition, the exact effect that 3MA may have on the cells in the combination treatment would need to be determined (such as induction of p70S6K activity [46]). As inhibitors of PI3K, the loss of this signalling cascade may have further reaching consequences than just autophagy inhibition itself. Further investigation needs to be done to determine whether the increase in autophagosomes observed during ESE-15-ol exposure is due to an increase in autophagy induction or due to abrogated flux (fusion or degradation).

\section{Conclusions}

Data from this study supports the concept that the novel $17-\beta$-estradiol analogue, ESE-15-ol, induces both apoptosis and autophagy in MCF-7 and MDA-MB-231 cells. Results obtained from the morphological studies indicated that 3MA incompletely blocked autophagy, and thereby increased cell survival. Flow cytometry was used to quantify the autophagy inhibition and increased cell viability. This in vitro study revealed that 3MA-mediated inhibition of autophagy increased cell viability of MCF-7 and MDA-MB-231 cells when exposed to ESE15-ol. Thus it is proposed that the ESE-15-ol-induced autophagic process in MCF-7 and MDA-MB-231 cells contributes to the novel compounds' cytotoxic effect by inducing programmed cell death type II, as opposed to conferring resistance to the neoplastic cells to drug exposure as a mechanism to compensate for cellular distress. Further quantification of the contribution of autophagy in cell death induction in response to the novel compound, as well as its role in possible tumor resistance will be carried out in future in vitro and in vivo studies.

\footnotetext{
Abbreviations

2-ME: 2-methoxyestradiol; 2MEOE2bisMATE: 2-methoxyestradiol-bissulfamate; 3MA: 3-methyladenine; Akt: protein kinase B; ANOVA: analysis of variance; $\mathrm{BCl}-2$ : B cell lymphoma 2; CAll: carbonic anhydrase II; CO: colorado; CO2: carbon dioxide; DMEM: dulbecco's Minimum Essential Medium Eagle; DMSO: dimethyl sulfoxide; DNA: deoxyribonucleic acid; DR5: death receptor 5; $E_{2}$ : estradiol; ESE-15-ol: 2-ethyl-3-O-sulpamoyl-estra-1,3,5(10),15-tetraen17-ol; ESE-15-one: 2-ethyl-3-O-sulpamoyl-estra-1,3,5(10),15-tetraen-17-one; ESE-16: 2-ethyl-3-O-sulphamoyl-etsra-1,3,5 (10) 16-tetraene; FCS: fetal calf serum; FL1: flow channel 1; FL3: flow channel 3; HepG2: human heptoma cells; HIF-1a: hypoxia-inducible factor -1a; HT1080: fibrosarcoma cell line; $\mathrm{IG}_{50}$ : half maximum growth inhibitory concentrations; LC3: microtubuleassociated protein 1A/1B-light chain 3; MA: Massachusetts; MCF-7: human adenocarcinoma breast cancer cell line; MDA-MB-231: metastatic human adenocarcinoma breast cancer cell line; MDC: monodansylcadaverine; MTOC: microtubule-organising centre; mTor: mechanistic target of rapamycin; PI: propidium iodide; PI3 K: phosphatidylinositide-3-kinase; PI3P: phosphatidylinositol-3-phosphate; PlasDIC: polarization-optical transmitted light differential interference light microscopy; PS: phosphatidylserine; SAC: spindle assembly checkpoint; USA: United States of America.
}

\section{Authors' contributions}

$M V, E N, A M J$ and AET conceived and designed the experiments; MV and EN performed the experiments; MV analyzed the data; AMJ and AET contributed reagents/materials/analysis tools and supervised the project; MV wrote the paper. All authors read and approved the final manuscript.

\section{Acknowledgements}

Prof AM Joubert and Dr. AE Theron for general support. This work was supported by Grants from the Medical Research Council of South Africa, the Cancer Association of South Africa, National Research Foundation and the Struwig-Germeshuysen Cancer Research Trust of South Africa.

\section{Competing interests}

The authors declare that they have no competing interests.

\section{Availability of data and materials}

Please contact author for data requests.

\section{Funding}

Prof. AM Joubert and Dr. AE Theron for general support. This work was supported by Grants from the Medical Research Council of South Africa, the Cancer Association of South Africa, National Research Foundation and the Struwig-Germeshuysen Cancer Research Trust of South Africa.

Received: 12 April 2016 Accepted: 28 November 2016

Published online: 08 December 2016

\section{References}

1. Lewis J, Thomas T, Pestell R. Differential effects of 16a-hydroxyestrone and 2-methoxyestradiol on cyclin $\mathrm{d} 1$ involving the transcription factor atf- 2 in mcf-7 breast cancer cells. J Mol Endocrinol. 2005;34:94-105.

2. Fishman J, Bradlow H, Gallagher T. Oxidative metabolism of estradiol. J Biol Chem. 1960;235:3104-7.

3. Li L, Bu S, Bäckström T, Landström M, Ulmsten U, Fu X. Induction of apoptosis and $\mathrm{G} 2 / \mathrm{m}$ arrest by 2-methoxyestradiol in human cervical cancer HeLaS3 cells. Anticancer Res. 2004;24:873-80.

4. Leese MP, Leblond B, Smith A, Newman SP, Di Fiore A, De Simone G, Supuran CT, Purohit A, Reed MJ, Potter BVL. 2-substituted estradiol bissulfamates, multitargeted antitumor agents: synthesis, in vitro sar, protein crystallography, and in vivo activity. J Med Chem. 2006;49:7683-96.

5. Stander B, Marais S, Vorster C, Joubert A. In vitro effects of 2-methoxyestradiol on morphology, cell cycle progression, cell death and gene expression changes in tumorigenic mcf-7 breast epithelial cell line. J Steroid Biochem Mol Biol. 2010;119:149-60.

6. Visagie M, Theron A, Mqoco T, Vieria W, Prudent R, Martinez A, Lafanechere L, Joubert A. Sulphamoylated 2-methoxyestradial analogues induce apoptosis in adenocarcinoma cell lines. PLoS ONE. 2013;8:e71935. doi:10.71371/journal.pone.0071953.

7. Zhou N, Zhu X, Zhou J, Li M, Zhang X, Huang P, Jiang W. 2-Methoxyestradiol induces cell cycle arrest and apoptosis of nasopharyngeal carcinoma cells. Acta Pharmacol Sin. 2004:25:1515-20.

8. Potapenko O, Zemskova M, Verin A, Zemskov E. Microtubule disruptor 2-methoxyestradiol has pro-inflammatory effect on human pulmonary endothelial cells. In: Inflammation and vascular permeability. New York: American Thoracic Society; 2014. pp A3268.

9. Stander BA, Joubert F, Tu C, Joubert AM. In vitro evaluation of ese-15-ol, an estradiol analogue with nanomolar antimitotic and carbonic anhydrase inhibitory activity. PLoS ONE. 2012;7:e52205.

10. Gascoigne K, Taylor S. How do anti-mitotic drugs kill cancer cells? J Cell Sci. 2009;122:2579-85.

11. Theron A, Prudent R, Nolte E, Bout I, Punchoo R, Marais S, du Toit P, Hlophe $Y$, Papendorp D, Lafanechère $L$, et al. Novel in silico-designed estradiol analogues are cytotoxic to a multidrug-resistant cell line at nanomolar concentrations. Cancer Chemother Pharmacol. 2014;75:431-7.

12. Elger W, Schwarz S, Hedden A, Reddersen G, Schneider B. Sulfamates of various estrogens are prodrugs with increased systemic and reduced hepatic estrogenicity at oral application. J Steroid Biochem Mol Biol. 1995;55:395-403. 
13. Winum J, Scozzafava A, Montero J, Supuran C. Sulfamates and their therapeutic potential. Medic Res Rev. 2005;25:186-228.

14. Genis C, Sippel K, Case N, Cao W, Avvaru B, Tartaglia L, Govindasamy L, Tu C, Agbandje-McKenna M, Silverman D, et al. Design of a carbonic anhydrase ix active-site mimic to screen inhibitors for possible anticancer properties. Biochemistry. 2009;48:1322-31.

15. Fukumura D, Jain R. Tumor microenvironment abnormalities: causes, consequences, and strategies to normalize. J Cell Biochem. 2007;101:937-49.

16. Lees E. Cyclin dependent kinase regulation. Curr Opin Cell Biol. 1995;7:773-80.

17. Johnson B, Ober W, Garrison C, Silverthorn A. Human physiology: an integrated approach. 5th ed. New York: Pearson; 2010.

18. Vermes I, Haanen C, Reutelingsperger C. Flow cytometry of apoptotic cell death. J Immunol Methods. 2000;243:167-90.

19. Ravikumar B, Berger Z, Vacher C, O'Kane C, Rubinsztein D. Rapamycin pretreatment protects against apoptosis. Hum Mol Genet. 2006;15:1209-16.

20. Meléndez A, Levine B. Autophagy in C. Elegans. Beijing: Worm Book; 2009 .

21. Yang $Z$, Chee $C$, Huang $S$, Sinicrope $F$. The role of autophagy in cancer: therapeutic implications. Mol Cancer Ther. 2011;10:1533.

22. Bandyopadhyay U, Kaushik S, Varticovski L, Cuervo A. The chaperonemediated autophagy receptor organizes in dynamic protein complexes at the lysosomal membrane. Mol Cell Biol. 2008:28:5754-63.

23. Wu YT, Tan H. Dual role of 3-methyladenine in modulation of autophagy via different temporal patterns of inhibition on class $i$ and iii phosphoinositide 3-kinase. J Biol Chem. 2010;285:10850-61.

24. Tran A, Ramalinga M, Kedir H, Clarke R, Kumar D. Autophagy inhibitor 3-methyladenine potentiates apoptosis induced by dietary tocotrienols in breast cancer cells. Euro J Nutr. 2014;54:265-72.

25. Ito S, Koshikawa N, Mochizuki S, Takenaga K. 3-Methyladenine suppresses cell migration and invasion of ht 1080 fibrosarcoma cells through inhibiting phosphoinositide 3-kinases independently of autophagy inhibition. Int J Oncol. 2007;31:261-8.

26. Li J, Hou N, Faried A, Tsutsumi S, Kuwano H. Inhibition of autophagy augments 5 -fluorouracil chemotherapy in human colon cancer in vitro and in vivo model. Euro J Cancer. 2010;46:1900-9.

27. Xie $B$, Zhao H, Yao $S$, Zhuo D, Jin B, Lv D, Ai Z. Autophagy inhibition enhances etoposide-induced cell death in human hepatoma g2 cells. Inter J Mol Med. 2011;27:599-606.

28. Bonet-Ponce L, Saez-Atienzar S, Casa C, Sancho-Pelluz J, Barcia JM, Martinez-Gil N, Nava E, Jordan J, Romero FJ, Galindo MF. Rotenone induces the formation of 4-hydroxynonenal aggresomes: role of ROS-mediated tubulin hyperacetylation and autophagic flux disruption. Mol Neurobiol. 2015;53:1-15.

29. Aniara. Crystal violet dye elution. http://www.aniara.com/pdf/INSAKCV96.pdf (Feb 26).

30. Gillies R, Didier N. Determination of cell number in monolayer cultures. Anal Biochem. 1986;159:109-13.

31. Krishan A. Rapid flow cytofluorometris analysis of mammalian cell cycle by propidium iodide staining. J Cell Biol. 1975;66:188-93.
32. Michaels S. Flow cytometry and sorting. http://www.stmichaelshospital. com/research/facilities/flow-cytometry-viability-apoptosis.php (Feb 27).

33. Mizushima N, Yoshimori T. How to interpret LC3 immunoblotting. Autophagy. 2007;3:542-5.

34. Niemann A, Takatsuki A. The lysosomotropic agent monodansylcadaverine also acts as a solvent polarity probe. J Histochem Cytochem. 2000;48:251-8.

35. Vasquez RJ, Howell B, Yvon AM, Wadsworth P, Cassimeris L. Nanomolar concentrations of nocodazole alter microtubule dynamic instability in vivo and in vitro. Mol Biol Cell. 1997;8:973-85.

36. Theron J, Nolte E, Lafanechère L, Joubert AM. Molecular crosstalk between apoptosis and autophagy induced by a novel 2-methoxyestradiol analogue in cervical adenocarcinoma cells. Cancer Cell Int. 2013;13:87.

37. Visagie M, Joubert A. The in vitro effects of 2-methoxyestradiol-bis-sulfphamate on cell number, mebrane integrity and cell morphology, and the possible induction of apoptosis and autophagy in a non-tumorogenicbreast epithelial cell line. Cell Mol Biol Lett. 2010;15:564-81.

38. Stander BA, Joubert F, Joubert A. Docking synthesis and in vitro evaluation of antimitotic estrone analogs. Chem Biol Drug Design. 2011;77:173-81.

39. Wolmarans E, Mqoco T, Stander A, Nkandeu S, Sippel K, McKenna R, Joubert A. Novel estradiol analogue induces apoptosis and autophagy in esophageal carcinoma cells. Cell Mol Biol Lett. 2014;19:98.

40. Stander BA, Joubert F, Tu C, Sippel KH, McKenna R, Joubert A. Signaling pathways of ESE-16, an antimitotic and anticarbonic anhydrase estradiol analog, in breast cancer cells. PLoS ONE. 2013;8:e53853.

41. Visagie M, Mqoco T, Joubert A. Sulphamoylated estradiol analogue induces antiproliferative activity and apoptosis in breast cell lines. Cell Mol Biol Lett. 2012;17:549

42. Visagie MH, Stander BA, Birkholtz L, Joubert AM. Short communication: effects of a 17-beta estradiol analogue on gene expression and morphology in a breast epithelial adenocarcinoma cell line: a potential antiproliferative agent. Biomed Res. 2013;24:525-30.

43. Yang X, Yu D-D, Yan F, Jing Y-Y, Han Z-P, Sun K, Liang L, Hou J, Wei L-X. The role of autophagy induced by tumor microenvironment in different cells and stages of cancer. Cell Biosci. 2015;5:14.

44. Klionsky DJ, Abdelmohsen K, Abe A, Abedin MJ, Abeliovich H, Acevedo Arozena A, Adachi H, Adams CM, Adams PD, Adeli K, et al. Guidelines for the use and interpretation of assays for monitoring autophagy. Autophagy. 2016;12:1-222.

45. Menzies FM, Moreau K, Puri C, Renna M, Rubinsztein DC. Measurement of autophagic activity in mammalian cells. In: Current protocols cell biology. New York: Wiley; 2001.

46. Desai BN, Myers BR, Schreiber SL. Fkbp12-rapamycin-associated protein associates with mitochondria and senses osmotic stress via mitochondrial dysfunction. Proc Natl Acad Sci USA. 2002;99:4319-24.

\section{Submit your next manuscript to BioMed Central and we will help you at every step:}

- We accept pre-submission inquiries

- Our selector tool helps you to find the most relevant journal

- We provide round the clock customer support

- Convenient online submission

- Thorough peer review

- Inclusion in PubMed and all major indexing services

- Maximum visibility for your research

Submit your manuscript at www.biomedcentral com/submit
BioMed Central 